\title{
Subjective and objective quality and choice of hospital: Evidence from maternal care services in Germany*
}

\author{
Daniel Avdic ${ }^{\dagger}$ \\ Giuseppe Moscelli \\ Ieva Sriubaite \\ Adam Pilny ${ }^{\S}$
}

August 20, 2019

\begin{abstract}
We study patient choice of healthcare provider based on both objective and subjective quality measures in the context of maternal care hospital services in Germany. Objective measures are obtained from publicly reported clinical indicators, while subjective measures are based on satisfaction scores from a large and nationwide patient survey. We merge both quality metrics to detailed hospital discharge records and quantify the additional distance expectant mothers are willing to travel to give birth in maternity clinics with higher reported quality. Our results reveal that patients are on average willing to travel $0.1-2.7$ additional kilometers for a one standard deviation increase in quality. Patients respond to both objective and subjective quality measures, suggesting that patient satisfaction scores may constitute important complements to clinical indicators when choosing provider.
\end{abstract}

Keywords: competition, provider choice, maternal care, quality.

JEL Classifications: C25, D82, H51, I11, I18.

*We thank the editor, two anonymous referees, Matthias Bäuml, Tuğba Büyükdurmuş and seminar participants at the RGS doctoral conference in Dortmund, SMYE conference in Halle an der Saale, LAGV conference in Aix-en-Provence, ESPE conference in Glasgow, the Annual Lithuanian Economics Meeting 2017 in Vilnius, and EEA conference in Lisbon for valuable comments and suggestions. We are also grateful to Tautvydas Januškevičius and Joseph Montalbo for excellent SQL programming and research assistance. Financial support from the Federal Ministry of Education and Research (BMBF) is gratefully acknowledged.

${ }^{\dagger}$ Corresponding Author: Centre for Health Economics, Monash Business School, Monash University Level 5, Building H, Caulfield Campus, 900 Dandenong Road, Caulfield East VIC 3145, Australia. Phone: +61 (0)3 9905 8152. E-mail: daniel.avdic@monash.edu.

${ }^{\ddagger}$ School of Economics, University of Surrey, Guildford, UK.

§RWI - Leibniz-Institut für Wirtschaftsforschung.

${ }^{\top} \mathrm{CINCH}$ and University of Duisburg-Essen. 


\section{Introduction}

The role played by quality as a factor explaining patients' choices of healthcare provider is a key component of the quality-competition theory, according to which providers have incentives to compete on quality when prices are fixed (Gaynor, 2006; Brekke et al., 2014). However, hospital competition on quality is possible only if demand for healthcare is not inelastic with respect to quality. As such, flexible patient choice of provider has been introduced in many healthcare systems across the world as a way to make healthcare demand more responsive to quality (Propper, 2018). Over the last decade, a number of studies have evaluated the association between quality and choice for elective care, finding that patient choice is to some extent responsive to quality (see, e.g., Pope, 2009; Varkevisser et al., 2012; Moscone et al., 2012; Santos et al., 2016; Gaynor et al., 2016; Moscelli et al., 2016) ${ }^{1}$. However, most studies to date have only considered clinical quality indicators.

In this paper we empirically investigate to what extent healthcare consumers vary in their choices of provider depending on the nature of the reported quality information. Specifically, we relate the choices of maternity clinics of expectant mothers to "objective" (clinical indicators) and "subjective" (patient satisfaction scores) performance measures using rich German data from administrative hospital discharge records linked to publicly available information about provider quality ${ }^{2}$. We focus on maternal care in Germany for several reasons: first, healthcare consumers in Germany are entirely free to choose hospital due to the universal health insurance system (which covers treatment in all hospitals) and the absence of a formal gate-keeping system (which regulates access into specialized care) ${ }^{3}$. Furthermore, the market for hospital childbirths is highly competitive with many producers and consumers of the service ${ }^{4}$. Finally, consumers in this market are likely to exert effort to make substantiated choices because they value any information that

\footnotetext{
${ }^{1}$ This result also holds in other settings such as the choice of health insurance plans with higher reported ratings. See, e.g., Beaulieu (2002); Wedig and Tai-Seale (2002); Scanlon et al. (2002); Jin and Sorensen (2006); Chernew et al. (2008); Bünnings et al. (2017).

${ }^{2}$ We define an objective, relative to a subjective, quality indicator as a performance measure which is not based on patients' own experiences or perceptions (e.g., rates of obstetric trauma).

${ }^{3}$ See, e.g., Busse and Blümel (2014) for a review of healthcare provision in Germany.

${ }^{4}$ Germany has the highest density of hospital beds in Europe. See https://www.destatis. de/Europa/EN/Topic/PopulationLabourSocial/Health/HospitalBeds.html.
} 
allows them to scrutinize their options over the course of their pregnancy ${ }^{5}$. Thus, the context of German maternal care suggests a close to optimal market setting where high-stakes patients are able to make informed choices between competing providers.

Our empirical analysis entails the use of three merged datasets from Germany. First, we use a ten percent nationally representative sample of all German hospital births for years 2009-2012 from a rich patient-level dataset of hospital discharge records, including a wide range of patient characteristics, services, clinical outcomes, and geographical locations of both hospitals and patients. We link this information to a set of objective quality indicators taken from standardized public report cards that all hospitals are required to provide. These report cards disclose relevant information for prospective patients, such as availability of medical services, clinical patient outcomes, capacity and competency of the medical staff. Finally, we complement the objective quality indicators with subjective quality information in the form of patient satisfaction scores from a nationwide survey administrated by one of Germany's largest public health insurance providers. The survey includes information on patients' satisfaction with their medical treatment, staffing, communication, organization, and accommodation in the hospital. Linking the hospital discharge records to the quality indicators in this manner allows us to directly use information that prospective patients have access to when choosing provider in contrast to relying on indirect information derived from, for example, hospital episodes.

We first estimate a simple linear probability model for the dichotomous choice between the closest hospital and any other hospital in a pre-defined choice set as a function of the former hospital's distance and quality. We subsequently model patient choice structurally using a conditional logit model from which we are able to compute marginal utilities to provide a direct estimate of a patient's willingness to travel (WTT) to a provider with higher reported quality. To this end, we use information on the distance between an individual's home and the chosen hospital to construct a measure of a representative patient's WTT for a given improvement in reported quality.

Our results indicate that patients generally respond to hospital quality,

\footnotetext{
${ }^{5}$ Giving birth is an activity frequently involving a substantial amount of anxiety for the patient. For example, pregnancy-related anxiety (PrA) is a disorder affecting 14 percent of all childbearing women (see, e.g., Alder et al., 2007; Blackmore et al., 2016).
} 
but also that responses vary substantially across quality indicators. Patients appear to respond to subjective quality also after conditioning on objective quality, suggesting that patient satisfaction scores provide a complementary source of information about the performance of a hospital that goes beyond established clinical indicators. We estimate that, depending on the specific quality indicator, an expectant mother is on average willing to travel an additional $0.1-2.7$ kilometers (0.2-4.5 minutes by car) to give birth in a hospital with a one standard deviation higher reported quality. This corresponds to a WTT of up to one-third of the average distance to the closest hospital for individuals in our sample. Our findings are largely robust to a set of sensitivity checks with respect to model specification, choice set and variable definitions. Despite somewhat attenuated coefficients, most of our results still hold when we incorporate hospital fixed effects in our model to account for time-invariant unobserved heterogeneity in hospital quality.

The literature on the competition-quality-choice nexus, upon which many of today's healthcare systems are built, is relatively scarce but growing ${ }^{6}$ and only a few papers have explicitly considered the trade-off between distance and quality ${ }^{7}$. We contribute to this important area of research mainly in two ways: First, we compare how patients respond to two qualitatively different dimensions of quality in their choice of healthcare provider for maternal delivery services. To our knowledge, while some studies have found that distance to the hospital has a significant effect on patients' choice (Porell and Adams, 1995; Sivey, 2012), only three studies (Moscone et al., 2012; Pilny and Mennicken, 2014; Gutacker et al., 2016) analyzed the influence of social interactions and subjective quality on patient's choice of hospital. In this work, however, the contrast of the effects of objective and subjective quality is in many ways different from the one analyzed by Gutacker et al. (2016). The subjective quality that we use captures patients' satisfaction across various hospital organizational domains, whereas in Gutacker et al. (2016) it is a measure of change in the patient's health status captured by routinely collected Patient Reported Outcomes Measures (PROM) like the Oxford Hip Score (OHS). In other words, the subjective quality indicators in our paper are

\footnotetext{
${ }^{6}$ See, e.g., Hodgkin (1996); Mukamel and Mushlin (1998); Baker et al. (2003); Cutler et al. (2004); Dranove and Sfekas (2008); Bundorf et al. (2009); Pope (2009); Werner et al. (2012); Varkevisser et al. (2012); Santos et al. (2016); Gaynor et al. (2016)

${ }^{7}$ See, e.g., Tay (2003); Jung et al. (2011); Beckert et al. (2012); Pilny and Mennicken (2014); Santos et al. (2016); Moscelli et al. (2016); Gutacker et al. (2016)
} 
proxies of non-clinical hospital quality. Using non-clinical subjective quality indicators has several advantages. It differs from previous literature, shedding light on the role that the perception of organizational and management quality has in the choice of elective hospital care; a question related and possibly preliminary to the one investigated by Bloom et al. (2015). It also represents a general measure of the broad quality of hospitals, thus being a sensible quality measure with respect to the choice of hospital service we analyze, whereas a subjective clinical measure like the OHS would be unsuitable to use, even if available, given that pregnancy is not a disease like osteoarthritis. Moreover, and differently from the OHS and other PROMs, a non-clinical subjective quality measure is less prone to the confounding bias due to differences in the post-treatment health status ${ }^{8}$.

Second, we contribute to the literature on the determinants of women's choice of birth clinic which has previously only rarely been investigated. O'Cathain et al. (2002) report evidence for Wales that a large minority of women giving birth did not feel like they exercised an informed choice in their maternity care. They show that evidence based leaflets were not effective in promoting informed choice in women using maternity services from a sample of 13 maternity units in Wales. Moreover, Wagle et al. (2004) show that distance to hospital and higher socioeconomic status are the main drivers of choice of place of maternal delivery (i.e., home versus hospital) in Nepal, but the study does not include any quality measure. Differences in healthcare experience or environment at critical times have also been found to affect psychological status of the mothers during pregnancy (Jomeen and Martin, 2008). Our results suggest that expectant women are highly responsive to reported quality when choosing clinic to give birth in, but also that the particular performance indicator appears to be crucial for the magnitude of the response.

The paper is organized as follows. The next section provides a summary of the relevant characteristics of the German healthcare system. Section 3 describes the data we use for our empirical analysis. Section 4 outlines our econometric framework. Section 5 reports results from estimation and section 6 concludes.

\footnotetext{
${ }^{8}$ Such bias may arise when the patients' health status change is driven not just by the quality of the treating hospital, but by the quality of other healthcare services (e.g., good or bad rehabilitation units, family doctors, osteopaths, etc.) located in the same catchment area of the treating hospital and playing a significant role in patients' post-surgical recovery.
} 


\section{Institutional context}

The German healthcare system is jointly organized by federal and state level institutions and provides healthcare for all citizens and permanent residents. The German health insurance system is characterized by the coexistence of public statutory health insurance (SHI) and substitute private health insurance (PHI). Access to healthcare is ensured by mandatory membership in one of the approximately 110 SHI funds or 50 PHI funds ${ }^{9}$. The SHI covers about 90 percent of the German population ${ }^{10}$. In the SHI family insurance, nonworking spouses and dependent children under 25 years are covered free of charge. Further exemptions from insurance premiums apply for students and unemployed. Insurance under the SHI is mandatory for employees with gross wage earnings below a defined threshold ( $€ 59 \mathrm{~K} / \$ 73 \mathrm{~K}$ annually in 2018 ). Specific groups of the population may opt out of SHI and buy substitute PHI or remain publicly insured as voluntary members, including high-income earners, self-employed and civil servants. Each SHI fund only offers one standardized health plan, which by law comprises full coverage of healthcare services and free choice of healthcare provider for all types and levels of care. By contrast, PHI providers are allowed to offer highly diverse health plans with varying components, such as co-payment levels and complementary care services. In general, PHI health plans also offer full coverage and include free hospital of treatment choice. However, PHI providers do not have to contract with healthcare providers and do not negotiate tariffs and prices as in the SHI. The maximum fee providers may charge for the treatment of PHI clients is regulated by the German Federal Ministry of Health (Wasem et al., 2004).

A set of regulations have been implemented in order to maintain and improve high levels of care quality delivered by healthcare providers. For example, all providers are obliged to establish a quality management system based on continuous medical education for all physicians as well as a health technology assessment for drugs and medical procedures. Moreover, minimum case volume requirements of complex inpatient procedures force hospitals to adapt to the development of new healthcare technologies to stay competitive. The overall treatment process as well as the outcomes are regularly

\footnotetext{
${ }^{9}$ Numbers as of January 2019.

${ }^{10}$ Pilny et al. (2017) provide a detailed overview about the German SHI and characteristics of its clients.
} 
controlled through a mandatory quality reporting system (Busse, 2008; Busse and Blümel, 2014).

Large parts of German hospital policy are decentralized to the level of the 16 federal state governments (Länder). In particular, the state governments are responsible for hospital planning, meaning that they decide on the extent, location and specialization of hospitals in their respective region. To this end, each state assembles a hospital plan and schedules the allocation of hospital capacities, investment funding and, to some extent, quality requirements for particular departments (Karmann and Roesel, 2017; Pilny, 2017). Hospitals that are included in a state's hospital plan are, since 2006, legally obliged to publish standardized quality report cards $^{11}$. Individuals are free to choose the healthcare provider for their next elective hospitalization among those hospitals included in a hospital plan, or those hospitals that contract with the SHI. The dissemination of hospital quality among the public is a key strategy used by policy makers in the competitive hospital market to stimulate choice among healthcare recipients.

The performance indicators in the standardized quality report cards are analyzed by independent and impartial institutes: the Institute for Quality and Patient Safety (BQS), the Institute for Applied Quality Improvement and Research in Healthcare (AQUA), and state-level specialized groups providing various services, such as individual feedback for hospitals, to assure high quality standards in the German healthcare market ${ }^{12}$. However, the quality report cards contain technical terms too complex to understand without significant clinical knowledge. Therefore, with the aim of giving patients the opportunity to form an opinion about hospital quality in a more digestible format, several web-based hospital comparison portals have been launched to provide a comprehensive and easily accessible hospital quality ranking for prospective patients.

\footnotetext{
${ }^{11}$ Hospitals not included in a hospital plan can still contract with the SHI, in which case they are also legally obliged to publish quality report cards. Together these hospitals comprise about 90 percent of all hospitals and 99 percent of all bed capacities in the market.

${ }^{12} \mathrm{BQS}$ managed the development and implementation of the external quality assurance system in Germany from 2001 to 2009, after which AQUA took over responsibility of this task (Busse et al., 2009).
} 


\section{Data}

\subsection{Inpatient care data}

Our empirical analysis uses patient-level data collected from hospital discharge records. The discharge data is based on diagnosis related group (DRG) reimbursement claims from a nationally representative sample of clients hospitalized between 2009 and 2012 and provided by a large German health insurance company. It includes a wide range of patient characteristics and comprehensive information about medical symptoms and administered treatments during the hospital visit. Clinical procedures performed by hospital physicians are coded according to the German classification of medical operations and procedures, Operationen- und Prozedurenschlüssel (OPS-12). To identify deliveries we use information on the cause for each admission, classified according to the World Health Organization's International Statistical Classification of Diseases and Related Health Problems (ICD-10 $)^{13}$.

Our population of interest is restricted to expectant mothers, 18 to 51 years of age, who gave birth at a maternity clinic located in a German hospital. We identify and sample patients in this age range with a singleton hospital delivery (in total around 250,000 deliveries), excluding births occurring outside of specialized departments (6,457 births or around $2 \%$ of the sample). Furthermore, we apply the Elixhauser (Elixhauser et al., 1998) index, computed from secondary medical diagnoses coded in the hospital data, to account for patient case-mix variation in terms of baseline health status ${ }^{14}$.

\subsection{Quality data}

We merge the inpatient data described in the previous section with a set of objective (OQ) and subjective (SQ) hospital quality indicators. These indicators are obtained from publicly available quality report cards, which all hospitals are by law required to provide, and a patient satisfaction survey

\footnotetext{
${ }^{13}$ Specifically, to identify deliveries we rely on ICD-10 codes: O80 (spontaneous delivery), O81 (delivery by forceps and vacuum extractor) O82 (delivery by cesarean section). We do not include multiple births in our analysis as they are considered risky deliveries and therefore subject to additional patient choice restrictions.

${ }^{14}$ The Elixhauser Comorbidity Index (ECI) distinguishes 31 different comorbidities and is often used as a risk-adjustment tool to predict hospital resource use and in-hospital mortality. For a list of comorbidities we include in our analysis, see Table A.1 in Appendix A.
} 
conducted by Techniker Krankenkasse $(\mathrm{TK})^{15}$, a large German SHI fund. In order to use quality information that prospective patients are most likely to use, we attempt to match as far as possible the criteria that the largest provider search platform in Germany, weisse-liste.de, bases its hospital ranking on $^{16,17}$. Appendix B provides a brief summary of the search features the website offers. However, it is important to note that the search portal has changed considerably over time and the information currently reported is quite different from the information provided during the time period our analysis covers.

One important aspect of the quality data is that it is reported biannually while we base our empirical analysis on annual information from the hospital discharge data. However, except for reducing empirical variation in our data, this does not constitute an important problem; it simply means that the information prospective patients have access to (which we are primarily interested in) is only updated every second year. Hence, for years where hospital quality was not updated, we retain the previous year's quality measures for each hospital. Below we give a brief description of the different quality indicators we use in our analysis.

\section{Quality report cards}

The quality report cards include detailed information on numbers of cases and procedures performed for each hospital department. Furthermore, they also provide an overview of available medical and nursing services, existence of special departments and equipment, and a set of quality indicators measuring the structure, process, and clinical outcomes in the hospital. We employ three OQ indicators that account for the quality of mandatory services in the

\footnotetext{
${ }^{15}$ Techniker Krankenkasse, founded in 1884, is one of Germany's largest social health insurance funds with a market share of about 14 percent, or 10 million clients (as of 2018).

${ }^{16}$ Weisse Liste is administered and maintained by the independent Bertelsmann Foundation and can be reached at https://www.weisse-liste.de. Pross et al. (2017) show that this online platform is frequently used for provider search in Germany. Although our main empirical specification does not exactly correspond to the variable definitions provided on weisse-liste.de, we have performed sensitivity analyses where our quality indicators are defined exactly as in the provider search platform, with qualitatively similar results.

${ }^{17}$ The subjective quality data provided by TK closely corresponds to a patient satisfaction survey conducted jointly by two other large German SHI funds, Allgemeine Ortskrankenkasse (AOK) and BARMER. Results from the latter are since 2012 published on weisse-liste.de while results from the former are published on a similarly widely used search portal: https://www.tk.de/tk/klinikfuehrer.
} 
maternity clinic. For consistency and ease of interpretation, we redefine these quality indicators in our empirical analysis so that a more positive value of the indicator always corresponds to higher quality. Furthermore, we include a set of indicators for available services that a given clinic offers in addition to mandatory maternal services. These are categorized into medical and nursing services and care specialties, respectively. Figure 1 presents the hospital distribution of the $\mathrm{OQ}$ indicators we include in our analysis. We define and explain the different quality indicators in turn below.

- Decision-to-delivery interval (DDI): In some cases an emergency cesarean section (ECS) is necessary in order to avoid irreversible damage to the infant (e.g., due to a lack of oxygen). The time span between the decision made for performing an ECS and the delivery is termed decisionto-delivery interval (DDI). According to current recommendations by the German Association for Gynecology and Obstetrics, the procedure should be performed within 20 minutes from the decision (DGGG, 1995). Hospitals may improve their process structure and organization through a reduction of DDI, for example, by providing stand-by facilities or staff for emergency duties. DDI is a process quality indicator calculated as

$$
\mathrm{DDI}=\frac{\text { All ECS deliveries with DDI below } 20 \text { minutes }}{\text { All ECS deliveries }} .
$$

The upper left panel of Figure 1 shows that almost all hospitals fully comply with a DDI below 20 minutes, i.e., a DDI indicator close to one.

- Availability of pediatrician: This process indicator refers to deliveries of premature infants with a gestational age (GA) of less than 37 weeks. In such cases, a pediatrician should attend the delivery and, if needed, provide necessary medical treatment to the newborn. This indicator is calculated as

$$
\text { Pediatrician }=\frac{\text { Access to pediatrician for births with GA }<37 \text { weeks }}{\text { All live births with GA }<37 \text { weeks }} .
$$

The distribution of this indicator is depicted in the upper middle panel of Figure 1. The figure shows that, while most hospitals have a pediatrician attending the vast majority of premature births, a substantial proportion do not have this option available at all. 
- Perineal tear: A perineal tear is a category of obstetric trauma which can be either light and curative (degree 1-2), or heavy and potentially chronic (degree 3-4). A heavy perineal tear is considered a preventable condition and, as such, a commonly used patient safety indicator for hospital quality. Since assisted and surgical deliveries are generally more risky births, this indicator is calculated as the ratio of the absence of heavy perineal tears among all spontaneous (i.e., non-assisted) births

$$
\text { Perineal tear }=\frac{\text { Absence of heavy perineal tear }}{\text { All spontaneous deliveries }} \text {. }
$$

The upper right panel of Figure 1 indicates that this outcome indicator exercises some variation across hospitals, although trauma rates are very unlikely to exceed 0.05 .

- Medical $\&$ Nursing services: Medical and nursing services (M-N Services) comprise a maximum of five complementary medical services a hospital may offer to expectant mothers: postpartum exercises, prenatal classes, infant care classes, breastfeeding advice, and additional midwife services (such as, e.g., water births). Figure 1 shows considerable variation across the maternity clinics with respect to the availability of these services.

- Care Specialties: Care specialties comprise a maximum of six complementary medical care specialties a hospital may offer to expectant mothers: prenatal diagnosis, surgery to ease delivery, assistance for high-risk pregnancies, advice for high-risk pregnancies together with a gynecologist, examination of diseases during the pregnancy, delivery, and the postpartum period, and (outpatient) delivery without a stay at the maternity clinic. Also for this indicator, Figure 1 shows substantial heterogeneity across maternity clinics.

\section{[Figure 1 about here]}

\section{Patient satisfaction}

Since 2006, TK has conducted a biannual survey of its clients' experiences with the care they received during their last hospital visit (Techniker Krankenkasse, 
$2010)^{18}$. The questionnaires are sent to a random sample of clients, with exceptions for individuals older than 80 years or in need of long-term care ${ }^{19}$. The survey consists of 41 questions partitioned into five categories where the participants are asked to rate their general satisfaction with the hospital visit, the results of treatment, the medical and nursing care, the communication with the hospital staff, and the organization and accommodation during the stay. Each question is evaluated by assigning points on a 12 point likert scale where more points indicate higher satisfaction. For ease of interpretation, answers were subsequently aggregated to the category level and rescaled to lie within the unit interval. Figure 2 shows the distributions for each satisfaction category.

\section{[Figure 2 about here]}

One potential issue with including all the five satisfaction categories of the TK survey simultaneously in our econometric model is that they are likely to be highly internally correlated. For example, a patient who was unsatisfied with the treatment she received is also more likely to respond more negatively with respect to general satisfaction. The first panel of Table 1 displays a correlation matrix across the five SQ indicators, confirming our suspicion that correlations across the different satisfaction categories are indeed very high. In comparison, the correlation coefficients across the OQ indicators, reported in the middle panel of the same table, are much smaller in magnitude. Finally, the bottom panel of Table 1 reports the correlations between OQ and SQ indicators. Interestingly, coefficients are in general negative, implying that hospitals with high OQ are associated with lower SQ and vice versa.

\section{[Table 1 about here]}

Due to the high correlations across the SQ indicators, we apply a principal component analysis (PCA) to extract and summarize the information content

\footnotetext{
${ }^{18}$ The hospital ranking and a document explaining the survey method can be found at https://www.tk.de/tk/klinikfuehrer.

${ }^{19}$ For each hospital between 150 and 1,000 patients were asked to participate in the survey. The response rates were quite high. For example, in 2010 more than $61 \%$ of surveyed patients responded (Pilny and Mennicken, 2014). However, the results were only reported when at least 60 questionnaires were fully completed. In our sample around $22 \%$ of all hospitals were unable to comply with this requirement. We account for missing quality information by including a dummy variable for each hospital where satisfaction data is unavailable.
} 
of the five categories into a single satisfaction score index ${ }^{20}$. Since results from estimation will be interpreted in units of standard deviations from standardized coefficients, the exact scaling of the variable is unimportant. Figure 3 illustrates the distribution of the composite subjective quality (CSQ) score.

\section{[Figure 3 about here]}

\subsection{Distance from hospital and choice sets}

To measure the geographical distance for a patient to a hospital with maternal care capacity, we use the 5-digit postal code of patient's registered home and the postal address of each hospital, both of which are available in our data ${ }^{21}$. We estimate both the travel distance and the travel time for each patienthospital combination using geocoding API software from Google ${ }^{\circledR}$ and Open Source Routing Machine (OSRM) ${ }^{22}$.

The left panel of Figure 4 presents the distance distribution from each patient's home to the closest hospital in our sample. The resulting distribution is highly right-skewed with a range between 0 to 30 kilometers and a mean of 7.8 kilometers. In addition, the right panel of the figure shows the distribution of the excess distance patients travel between the closest and the chosen hospital. Although the mean of the excess distribution is only three kilometers, it has a substantial range. For example, more than ten percent of patients travel at least ten kilometers more than necessary to give birth. This suggests that patients value other factors than only geographical distance when choosing hospital.

\footnotetext{
${ }^{20}$ Principal component analysis ( $\left.\mathrm{PCA}\right)$ is a statistical procedure that uses an orthogonal transformation to convert a set of observations of possibly correlated variables into a set of values of linearly uncorrelated variables called principal components. In our case, the number of principal components turns out to equal exactly one.

${ }^{21}$ This approach follows, e.g., Hentschker and Mennicken (2015, 2018); Mennicken et al. (2014) and implicitly assumes that patients travel from the geographic centroid of each 5 -digit postal code area corresponding to its geographic center. There are about 8,200 5digit postal code in Germany with a median size of $27 \mathrm{~km}^{2}$ and the vast majority below $100 \mathrm{~km}^{2}$. When interpreting the results from estimation, it is worth noting that there are no obvious reasons why any measurement errors arising from this simplification would be systematically related to quality indicators of individual hospitals. In fact, if patients and hospitals are randomly located with respect to the centroid of a given postal code, the measurement error would have zero unconditional expectation.

${ }^{22}$ For a documentation of the latter resource, see http://project-osrm.org/ and Huber and Rust (2016). We exclude a few cases where measuring the distance to a hospital was not possible, such as patients living on an island without a road connection to a hospital.
} 


\section{[Figure 4 about here]}

In order to estimate our choice model (described below), we define a choice set (i.e., a local hospital market) for each patient. To this end, we include all hospitals within a radius of 30 kilometers from the individual's place of residence (corresponding to the $90^{\text {th }}$ percentile of the sample distance distribution to the chosen hospital). Consequentially, since $10 \%$ of patients choose a hospital outside of their choice set, our sample is reduced to around 225,000 births. From this definition the maximum number of choices provided to any patient in our sample is $25^{23}$. Figure 5 shows a histogram displaying the share of patients in our sample who gave birth in hospitals ranked by distance from the patient's home. Roughly half of patients chose to give birth in their closest hospital, while the remaining patient share in a gradually declining fashion chose hospitals located farther away from their homes.

\section{[Figure 5 about here]}

To visualize the geographical variation in access to maternal care in Germany, Figure 6 provides two maps of Germany showing the average distance to the closest maternity clinic (left panel) and density of maternity clinics within a radius of $30 \mathrm{~km}$ (right panel) by postal code, respectively. While inhabitants of most parts of Germany have less than 30 kilometers to the nearest maternity clinic, the number of choices varies substantially across the country. The metropolitan areas of North Rhine-Westphalia, Hamburg, Berlin, Frankfurt, Stuttgart and Munich often have more than 25 choices while the sparsely populated areas in Eastern Germany often have less than five.

\section{[Figure 6 about here]}

Figure 7 presents the unconditional distribution of patients' choice of hospital ranked from best to worst in their choice set by quality indicator. For the purpose of presentation, we show only the ten highest-ranked hospitals as the shares of patients choosing lower ranked hospitals become very small. Although the intensity of the pattern varies across indicators, all measures exhibit a positive relationship between a hospital's reported quality and its

\footnotetext{
${ }^{23}$ We have evaluated the robustness of our results with respect to the definition of the choice set by estimating separate models for a maximum of 15 and 20 choices with very similar results.
} 
relative popularity. There are strong positive associations for the decision-todelivery interval, pediatrician availability, medical and nursing services and care specialties indicators, while patterns are less clear for the remaining quality indicators.

\section{[Figure 7 about here]}

\subsection{Sample summary statistics}

Table 2 reports sample summary statistics by different levels of data aggregation. From upper-left to lower-right the panels refer to variable means and standard deviations on the patient, choice-set, hospital and closest hospital levels, respectively. Around one-third of the roughly 225,000 births in our sample are classified as emergencies. To account for the fact that emergency patients are unlikely to have full discretion in their choice of hospital, we include an indicator variable for whether the hospital admission was coded as an emergency in our regression models. We also adjust for other factors that may have affected the individual's choice of maternity clinic, such as patient age and case-mix controls for the number of Elixhauser co-morbidity indicators, whether the admission occurred on the weekend or during rush hour, whether the patient lived in a rural or an urban postal code and whether the birth was coded as being risky or not. Summary statistics for these variables are reported in the two top panels of Table 2, corresponding to the level of the patient (left) and the choice set (right).

Table 2 also provides some summary statistics on the distance variables. Specifically, although the average patient had approximately eight kilometers (12 minutes) to the closest hospital, she nevertheless chose a hospital at a distance of 11 kilometers (14 minutes) from her home. Around one-half of the expectant mothers did not choose their closest hospital, but instead went to a hospital located at an additional three kilometers distance, on average. The corresponding figures for the choice sets closely resemble the individual level counterparts, except for a larger share of rural choice sets and increased distances and travel times to the closest and chosen hospitals, respectively. Our econometric approach (explained below) accounts for bias from such heterogeneity by only using within-individual variation across choices to estimate the parameters of the model ${ }^{24}$.

\footnotetext{
${ }^{24}$ To study potential heterogeneous effects between rural and urban choice sets and be-
} 
The two bottom panels of Table 2 present hospital-level summary statistics of the quality indicators we include in our analysis. The left panel refers to the universe of hospitals while the right panel only considers the closest hospital in each choice set. Around 22 percent of hospitals lacked information about SQ (see footnote 19). To handle this missing data issue and simultaneously keeping the choice sets intact, we impute a value of zero for each observation for which quality information is unavailable and include an binary indicator variable in our econometric model to distinguish these missing values from "true" zeros.

To avoid confounding between our quality indicators and other hospital characteristics, we include a set of control variables related to the (perceived) performance of a hospital in our models, such as ownership type and whether the hospital is a teaching or a university hospital. We also include a set of capacity-related variables, such as the number of midwives and nurses, number of beds and the share of specialized physicians in the hospital. Finally, to account for any time-invariant unobserved heterogeneity in perceived hospital quality, we estimate models with hospital fixed-effects.

\section{[Table 2 about here]}

\section{Econometric framework}

\subsection{Theoretical predictions}

We assume that a patient $i$ choosing a hospital $k=1,2, \ldots, K$ values both higher quality $(Q)$ and shorter distance $(D)$. However, the patient may restrict her search to providers within the same hospital market $j=1,2, \ldots, J$, yielding $k_{j}=1, \ldots, K_{j}$ choices for each of the $J$ hospital markets. Formally, patient utility is modeled by the additively separable utility function

$$
U_{i j k}=f\left(Q_{k_{j}}, D_{k_{j}}\right)+\varepsilon_{i j k}
$$

where we assume that utility is (weakly) increasing in the first and decreasing in the second argument. We also allow the patient to have heterogeneous

tween emergency and non-emergency admissions, we estimate models where these regressors are interacted with the quality indicators. The results from this analysis are provided in section 5.2 below. 
preferences for a particular hospital as long as these preferences are unrelated to $Q$ and $D$.

Assume that patient $i$ is choosing between two hospitals in the same hospital market ( $j$ subscript omitted), 1 and 2 , with corresponding utility functions

$$
\begin{aligned}
& U_{i}(1)=f\left(Q_{1}, D_{1}\right)+\varepsilon_{i 1}, \\
& U_{i}(2)=f\left(Q_{2}, D_{2}\right)+\varepsilon_{i 2},
\end{aligned}
$$

The probability that the patient will choose hospital 1 is then

$$
\begin{aligned}
p_{i 1}= & \operatorname{Pr}\left[U_{i}(1)>U_{i}(2)\right]= \\
& f\left(Q_{1}, D_{1}\right)-f\left(Q_{2}, D_{2}\right)+\mathbb{E}\left[\varepsilon_{i 1}-\varepsilon_{i 2}\right]>0 .
\end{aligned}
$$

Given identical preferences for the two hospitals, the last term collapses and the decision rule is to choose hospital 1 whenever $f\left(Q_{1}, D_{1}\right)>f\left(Q_{2}, D_{2}\right)^{25}$.

In order to define an economically relevant measure for the trade-off the patient is facing, we consider the additional distance an individual is willing to travel in order to obtain a given increase in quality, i.e., $\partial D / \partial Q>0$. Totally differentiating (1) we get (omitting subscripts)

$$
d U(Q, D)=(\partial U(Q, D) / \partial Q) d Q+(\partial U(Q, D) / \partial D) d D
$$

which is equivalent to

$$
\frac{d U(Q, D)}{d Q}=\partial U(Q, D) / \partial Q+(\partial U(Q, D) / \partial D) \frac{d D}{d Q}
$$

Since we evaluate the trade-off between quality and distance, implying that total utility is held constant, the left hand side is equal to zero and so

$$
\frac{\partial D}{\partial Q}=-\frac{\partial U(Q, D) / \partial Q}{\partial U(Q, D) / \partial D}
$$

where the right hand side term is the marginal rate of substitution of quality for distance, $M R S_{Q, D}$. Given a suitable empirical specification for individual utility, we can estimate the willingness to travel for a patient for a given increase in hospital quality.

\footnotetext{
${ }^{25}$ Generalizing to $k$ hospitals the corresponding decision rule is $p_{i k}=\operatorname{Pr}\left[U_{i k_{j}}>\right.$ $U_{i-k_{j}}$, all $\left.-k_{j} \neq k_{j}\right]$.
} 
Our hypotheses can be summarized as follows: (i) a patient's likelihood of choosing a particular hospital will increase with reported maternal care quality and decrease with the distance to the hospital (i.e., $f_{1}(Q, D)>0$ and $\left.f_{2}(Q, D)<0\right)$ and; (ii) a patient will trade off additional distance to a maternity clinic in a hospital with a higher reported quality, i.e., $\partial D / \partial Q>0$.

\subsection{Reduced form analysis}

We first consider a simple linear probability model (LPM) for choosing the closest hospital in the choice set as a function of hospital quality. Specifically, for individual $i$ in choice set $j$ and year $t$, the LPM is defined by

$$
\text { Closest }_{i j t}=\alpha_{0}+f\left(d_{j t}^{c} ; \alpha_{d}\right)+q_{j t}^{c l} \beta_{q}+X_{i t}^{\prime} \Theta_{X}+Z_{j t}^{c \prime} \Theta_{Z^{c}}+\bar{Z}_{j t}^{\prime} \Theta_{\bar{Z}}+\epsilon_{i j t},
$$

where Closest $_{i j t}$ is a binary indicator for whether a patient chose the closest hospital in her choice set ${ }^{26}$. Similarly, $d_{j t}^{c}$ and $q_{j t}^{c}$ indicate the distance (scalar) and quality (vector) of the closest hospital in the individual's choice set, where $f(\cdot)$ is a cubic polynomial function of $d_{j t}^{c}$ with corresponding parameter vector $\alpha_{d}$. Furthermore, $X_{i t}, Z_{j t}^{c}$, and $\bar{Z}_{j t}=N^{-1} \sum_{k} z_{j k t}$ are vectors of patient, closest hospital, and average choice set specific variables as reported in Table 2, respectively. Finally, $\epsilon_{i j t}$ is an assumed random regression error term. We cluster standard errors on the level of spatial planning regions (96 clusters) to account for any residual correlation across individuals living in the same region $^{27}$. We are primarily interested in the signs of the $\hat{\beta}_{q}$ vector, which inform us about whether an improvement in a given quality indicator of the closest hospital increases the likelihood of choosing it relative to other hospitals in the same choice set. Since higher values of all quality correspond to better quality, we expect all coefficients to be positive ${ }^{28}$.

\footnotetext{
${ }^{26}$ That is, Closest ${ }_{i j t}$ evaluates to one if the chosen hospital $k_{j}$ satisfies $k_{j}: d_{j k t}=$ $\min \left(d_{j t}\right) \forall k_{j t} \in(j, t)$.

${ }^{27}$ We have also clustered standard errors on the local (kreise) and the state (land) levels, yielding very similar results.

${ }^{28}$ We have also estimated models where we use the relative quality compared to the average quality in the choice set instead of including the absolute quality of the closest hospital. This alternative specification does not change our results to any important extent.
} 


\subsection{Structural choice modeling}

Inferences derived from estimation of the LPM in (7) are generally uninformative about the hospital distance-quality trade-off a patient faces. Therefore, we also consider a structural econometric framework for hospital choice based on estimation of a conditional logistic regression model. The advantage of this approach is that it allows us to derive and estimate the additional distance a patient is willing to travel to a hospital in exchange for an increase in reported quality.

Departing from our theoretical framework in (1), the random utility model specifies

$$
U_{i k t}=V_{i k t}+\xi_{k t}+\mu_{i k t} \quad \text { for }(i, k) \in j
$$

where utility of individual $i$ of choosing hospital $k$ in year $t$ in choice set $j$ is a linear function of observable individual and hospital characteristics $V_{i k t}$ (e.g., reported quality indicators), unobservable hospital characteristics $\xi_{k t}$ (e.g., hospital reputation), and unobserved individual heterogeneity, $\mu_{i k t}$ (e.g., patient preferences). Assuming that $\mu_{i k t}$ is i.i.d. and type I extreme value distributed, the probability that patient $i$ chooses hospital $k$ can be written on the logistic form as (see, e.g., Cameron and Trivedi, 2005)

$$
\begin{aligned}
p_{i k t}= & \operatorname{Pr}\left[y_{i t}=k\right]= \\
& \exp \left(V_{i k t}+\xi_{k t}\right)\left[\sum_{k^{\prime} \in j} \exp \left(V_{i k^{\prime} t}+\xi_{k^{\prime} t}\right)\right]^{-1}, \quad k=1, \ldots, K_{j},
\end{aligned}
$$

where the dependent variable $y_{i k t}$ is defined as

$$
y_{i k t}= \begin{cases}1 & \text { if } y_{i t}=k, \\ 0 & \text { if } y_{i t} \neq k\end{cases}
$$

Individual utility is assumed to be represented by the linear model

$$
\begin{aligned}
U_{i k t}=\sum_{p}^{P} \gamma_{p t}^{q} q_{k t}^{p} & +\sum_{s}^{S} \gamma_{s t}^{d} d_{i k t}^{s}+\sum_{p}^{P} \sum_{m}^{M} \gamma_{p m t}^{q x} q_{k t}^{p} \tilde{x}_{i m t} \\
& +\sum_{s}^{S} \sum_{m}^{M} \gamma_{m s t}^{d x} d_{i k t}^{s} \tilde{x}_{i m t}+\sum_{l}^{L} \gamma_{l t}^{z} z_{k t}^{l}+\nu_{i k t}
\end{aligned}
$$


where $q_{k t}^{p}$ refers to the $p$ th quality indicator and $d^{s}$ to the $s$ th polynomial order for the (cubic) distance relation. Furthermore, $\tilde{x}_{i m t}=x_{i m t}-\bar{x}_{m}$ is the meancentered value of the $m$ th individual characteristic with $\bar{x}_{m}=N^{-1} \sum_{t} \sum_{i} x_{i m t}$ and $z_{k t}^{l}$ is the $l$ th hospital characteristic reported in Table 2. The vector $\gamma=$ $\left(\gamma^{q}, \gamma^{d}, \gamma^{q x}, \gamma^{d x}, \gamma^{z}\right)$ comprises the set of coefficients to be estimated. Finally, the joint error term $\nu_{i k t}=\xi_{k t}+\epsilon_{i k t}$ is assumed to be i.i.d. conditional on included individual and hospital level control variables.

Endogeneity concerns could arise if, for example, private or teaching hospitals are perceived by individuals as being of different quality than public or non-teaching hospitals, or if lower quality hospitals are exiting the market due to fierce competition. We assume that our included hospital specific variables account for the former concern, and the fact that very few hospitals are closed during the relevant years suggests that the latter is unlikely to be a severe problem here ${ }^{29}$. Furthermore, the conditional logit model uses within-individual variation to estimate the model parameters, implying that any potential biases from choice-invariant factors (e.g., average distance to and quality of hospitals in the choice set) are effectively accounted for in the analysis. Nevertheless, in order to account for potential unobserved heterogeneity in (perceived) hospital quality, we also estimate models with hospital fixedeffects. The inclusion of hospital fixed-effects implies that empirical variation in quality across hospitals within a choice set are purged from the analysis and the model's parameters are exclusively estimated using changes within a hospital's quality indicators across time. Since the source of identifying variation is qualitatively different in the models with and without hospital fixed-effects, and consequently also the interpretation of the estimated parameters, we retain both specifications in the discussion of our results.

Mean-centering the individual patient characteristics allows us to both control for potential confounding factors and interpret the estimated $\gamma_{p t}^{q}$ and $\gamma_{s t}^{d}$ as marginal utilities with respect to quality and distance for a patient with average characteristics in a given year. From the conditional logit model, described by equations (8)-(11), we can thus produce an estimate of the will-

\footnotetext{
${ }^{29}$ According to the Federal German Statistical Office, there were 67 hospital market exits across Germany between 2009 and 2012, corresponding to around three percent of all German hospitals. Note that these numbers refer to all hospitals and not necessarily to hospitals with maternal health services. In addition, the total number of hospital beds barely changed from 503,341 to 501,475 ( -0.4 percent) over the same time period (Destatis, 2018, p.11).
} 
ingness to travel (WTT) for a representative patient to a hospital with a one standard deviation increase in the $p$ th reported quality measure as (see, e.g., Moscelli et al., 2016)

$$
\begin{aligned}
W T T(p) & =\sigma_{p} \frac{\partial d_{i k t}}{\partial q_{k t}^{p}}=\sigma_{p}\left(-\frac{\partial U_{i k t} / \partial q_{k t}^{p}}{\partial U_{i k t} / \partial d_{i k t}}\right) \\
& =\sigma_{p} \frac{-\gamma_{p t}^{q}}{\gamma_{1 t}^{d}+2 \gamma_{2 t}^{d} \zeta_{d}+3 \gamma_{3 t}^{d} \zeta_{d}^{2}},
\end{aligned}
$$

where the second equality is the negative of the marginal rate of substitution (see equation (6)) and the third equality is obtained from differentiation of (11) with a cubic distance representation. Furthermore, $\sigma_{p}$ is the standard deviation of the $p$ th quality measure and $\zeta_{d}$ is the average distance to the chosen provider for all patients over all years. To obtain standard errors for the WTT, we apply the delta method (see, e.g., Cameron and Trivedi, 2005).

\section{Results}

\subsection{Main results}

Table 3 reports results from estimation of the linear probability model for choosing the closest hospital in the choice set as specified in equation (7). In column (1) all OQ indicators are included together with a cubic distance polynomial and the full set of patient and hospital control variables from Table 2, while SQ is included through the five satisfaction categories in the TK survey, respectively. In column (2), SQ is instead included through the composite SQ score. Finally, the specification reported in column (3) additionally includes hospital fixed effects to account for time-invariant unobserved heterogeneity in hospital quality.

As expected, choosing the closest provider is negatively associated with distance and positively associated with the OQ indicators throughout the table. The estimated coefficients of the SQ categories in column (1) are only statistically distinguishable from zero for satisfaction with accommodation while the coefficients of the four other categories have negative signs, highlighting the issue of multicollinearity ${ }^{30}$. When we instead include the composite SQ

\footnotetext{
${ }^{30}$ Columns (1)-(5) of Table A.2 reports results, corresponding to the specification in column (3) of Table 3, where each satisfaction score category is included separately. All
} 
score in columns (2) and (3) we obtain a positive and, in the latter case, also statistically significant point estimate of the SQ indicator.

\section{[Table 3 about here]}

Table 4 reports the estimated coefficients from the conditional logit model, defined by equations (8)-(11), including the full set of controls from Table 2. As before, SQ is first included using the five satisfaction categories, in column (1), and subsequently through the composite score, in columns (2) and (3), respectively. Choice of hospital is again negatively correlated with distance and the higher order terms suggest a diminishing association as distance increases. Furthermore, all OQ indicators have a positive impact on hospital choice across the different specifications. The issue of multicollinearity is again visible from observing the highly variable coefficient values of the individual SQ categories in column (1), but positive and statistically significant in column (2). Effect sizes are substantially attenuated for D-D-I, pediatrician and the composite SQ score quality indicators when hospital fixed effects are included in column (3), which, together with lower statistical precision, render the impact of these variables statistically indistinguishable from zero ${ }^{31}$.

\section{[Table 4 about here]}

Finally, we use the estimated parameters from our conditional logit model to estimate the average $W T T$ for a one standard deviation increase in reported quality. The results are presented graphically in Figure 8 (without hospital fixed effects) and Figure 9 (with hospital fixed effects), where the left and right panels refer to the point estimates from the conditional logit model and the WTT estimates using equation (12), respectively.

From Figure 8, a one standard deviation increase in reported quality for the three process quality indicators (D-D-I, perineal tear and pediatrician

categories are individually positively associated with choosing the closest hospital, but, once all are included simultaneously in column (6), only one coefficient remains significantly distinguishable from zero.

${ }^{31}$ The inclusion of hospital fixed effects in the model implies that empirical variation in the outcome is restricted to within-hospital temporal changes in quality. This may restrict both the total variation in the model and in single regressors and lead to imprecisely estimated parameters. To study the extent of this problem, we analyzed the coefficient of variation $(\mathrm{CV})$ for each of the quality indicators to see how much variation remains after removing the cross-sectional variation. Table A.3 shows that the CV is quite low for several quality indicators, suggesting that they change little over time. 
availability) are associated with increases in the WTT of between 0.2 to 0.6 kilometers, while an equivalent increase in quality for the service categories increases WTT by 0.5 (Care Specialties) and 1.6 (Medical and Nursing Services) kilometers, respectively. Finally, the corresponding figure is 0.6 kilometers for the composite SQ score. Hence, the range of WTTs are highly variable and dependent on the specific quality indicator.

\section{[Figure 8 about here]}

Turning to the results with hospital fixed effects in Figure 9, WTTs are generally attenuated (0.1-0.2 kilometers), except for the service categories in which WTT estimates for Care Specialties and Medical and Nursing Services increase to 0.9 and 2.7 kilometers, respectively. Given that the mean difference between the closest and the chosen hospital is about three kilometers (see Table 2), this upper bound of the WTT does not appear to be an unreasonable estimate. Taken together, depending on the specific indicator, a statistically representative patient is willing to travel between virtually no distance at all to about one-third of the average distance to the closest hospital to reach a hospital with a one standard deviation higher reported quality.

\section{[Figure 9 about here]}

\subsection{Robustness checks}

We perform a falsification test to study whether our quality indicators pick up unobserved hospital quality not captured by the control variables we include in the model. Specifically, we use hospital-level information on mortality from heart attack patients, which is arguably irrelevant for the choice of maternity clinic of expectant mothers, to assess the extent to which such factors influence the choice of hospital for our sample. If such information is predictive of hospital choice, we might suspect that there are unobserved factors determining choice that we do not account for in the analysis. Table 5 reports the results from our main specification where we have included in-hospital and 30-days post-discharge acute myocardial infarction (AMI) mortality as additional regressors. Reassuringly, the choice of maternity clinic in our sample is not significantly associated with AMI mortality, irrespective of mortality definition. 


\section{[Table 5 about here]}

We have also evaluated the robustness of our results with respect to our definition of choice set and travel distance. The results are shown in Table 6 . The first four columns show the baseline specification using distance in kilometers with a maximum of 15 choices in each patient's choice set (columns 1 and 2) and with a maximum of 20 choices (columns 3 and 4), respectively. We also estimate models for a travel time-based definition (in minutes) with a maximum of 25 choices (columns 5 and 6). Our main findings do not change to any important extent when these definitions are changed.

\section{[Table 6 about here]}

To study heterogeneous effects across patient groups, we re-estimate the conditional logit model by additionally including interaction terms between our quality measures and indicators for whether the birth was classified as an emergency and whether the patient was residing in an urban area, respectively. Table 7 presents the results from this exercise. Columns (1) and (2) report level and interaction effects with the emergency indicator for each distance and quality indicator, where the former and latter set of parameters are interpreted as the magnitude of response from non-emergency cases and the additional impact from emergency cases, respectively. While the interaction coefficients with distance are estimated with negative signs, there is no evidence that emergency patients differ significantly from non-emergency patients in their preferences for distance. With respect to the set of quality indicators, one general discernible pattern is that indicators for clinical service capacity (DD-I, Pediatrician and Care Specialties) seem to be more relevant for the choice of emergency patients, while indicators for clinical quality (Perineal Tear and CSQ) are less relevant. This is an intuitive result given that the priority of emergency services should be to direct the patient to a provider with the necessary capacity to assist the delivery of high-risk births.

Heterogeneity with respect to urban and rural choice sets is presented in columns (3) and (4) of Table 7. The impact of distance for patients residing in urban choice sets has an effect size that is more than twice that of patients living in rural areas. This suggests that competition in this dimension is much greater in urban areas. The results for quality suggest, with the exception of maternal trauma, that patients living in urban areas do not have systematical different preferences than those living in rural areas. 


\section{[Table 7 about here]}

Finally, we test the robustness of our results by redefining the definition of the quality indicators more in line with the definition provided on weisseliste.de. Specifically, the information provided on the provider search portal defines a quality threshold for each of the treatment relevant indicators for which a hospital has "passed" if the quality is at least as good or better than the required quality threshold according to a specified reference value set by the responsible authority. The first two columns of Table 8 report results from our linear probability model where we have redefined all quality indicators in this way. Furthermore, the last two columns provide estimates of two general quality categories: Mandatory Quality Assurance and TreatmentRelated Services, defined as objective quality scores related to the quality and availability of services, respectively (see Appendix B for details). The results from this exercise show that the implications from our main analysis are largely unchanged.

\section{[Table 8 about here]}

\section{Conclusion}

We study patient choice of hospital with respect to both objective and subjective information about provider quality in the context of maternal care in Germany. Objective quality indicators are obtained from mandatory hospital quality report cards and subjective indicators are based on patient satisfaction scores from a large, nationwide patient survey. The quality information is linked to hospital discharge records including information on the place of residence of both patients and hospitals. We use the data to estimate econometric models of hospital choice to quantify the additional distance expectant mothers are willing to travel to give birth in a hospital of higher reported quality. Our results indicate that patients are on average willing to travel between 0.1 and 2.7 additional kilometers to obtain a one standard deviation increase in reported quality.

Our findings contribute to the existing literature on the determinants of consumer choice of healthcare provider. In line with previous findings, we obtain empirical evidence that prospective patients are responsive to quality; 
other papers have estimated a willingness to travel (WTT) of at most 0.9 kilometers (Gutacker et al., 2016) or 0.7 kilometers (Moscelli et al., 2016) for a one standard deviation increase in objective quality measures, related to elective hip replacement surgery. The magnitudes of the average WTTs, estimated with hospital fixed effects, for two of the objective quality measures (the number of Medical and Nursing Services and Care Specialties) in a given hospital, are large (2.7 and 0.9 kilometers, respectively) in comparison when compared to the WTTs estimated for other healthcare services in the literature, suggesting that there is scope for patient choice to respond to hospital quality. One reason for this strong patient response could be the importance that medical and nursing services can have for both the mother's and the child's health and wellbeing both before, during, and after childbirth ${ }^{32}$.

We also find that patients appear to value not only objective but also subjective quality information. This is an important finding since it highlights that there are dimensions of quality of care that are not subsumed within standard objective quality metrics despite their richness and variety. Subjective quality is in general negatively correlated with the objective quality indicators within a hospital, suggesting that hospitals with high clinical excellence, such as low risks of mortality or complications, perform relatively worse with respect to "softer" dimensions of quality, such as personal comfort, staff friendliness, etc., that might contribute to patient well-being in ways that are not captured by physical health events. Different quality measures may thus not necessarily be substitutes and could even involve conflicting information. Studying the mechanisms through which different provider quality indicators in the healthcare sector interact with each other and how this affects patient choice may be a fruitful area for future research.

\footnotetext{
${ }^{32}$ In Germany women tend to keep loyalty to the hospital where they gave birth. Anecdotal evidence is provided in e.g. Süddeutsche Zeitung (2017). Availability of such services may thus be important when making a long-term commitment to a hospital.
} 


\section{References}

Alder, J., Fink, N., Bitzer, J., Hösli, I. and Holzgreve, W. (2007). Depression and anxiety during pregnancy: a risk factor for obstetric, fetal and neonatal outcome? A critical review of the literature. The Journal of Maternal-Fetal \&s Neonatal Medicine, 20 (3), 189-209.

Baker, D. W., Einstadter, D., Thomas, C., Husak, S., H.Gordon, N. and Cebul, R. D. (2003). The Effect of Publicly Reporting Hospital Performance on Market Share and Risk-Adjusted Mortality at HighMortality Hospitals. Medical Care, 41 (6), 729-740.

Beaulieu, N. D. (2002). Quality information and consumer health plan choices. Journal of Health Economics, 21, 43-63.

Beckert, W., Christensen, M. and Collyer, K. (2012). Choice of NHSfunded Hospital Services in England. The Economic Journal, 122 (560), 400-417.

Blackmore, E. R., Gustafsson, H., Gilchrist, M., Wyman, C. and O'Connor, T. G. (2016). Pregnancy-related anxiety: Evidence of distinct clinical significance from a prospective longitudinal study. Journal of Affective Disorders, 197, 251-258.

Bloom, N., Propper, C., Seiler, S. and Van Reenen, J. (2015). The Impact of Competition on Management Quality: Evidence from Public Hospitals. The Review of Economic Studies, 82 (2), 457-489.

Brekke, K. R., Gravelle, H., Siciliani, L. and Straume, O. R. (2014). Patient choice, mobility and competition among health care providers. Developments in health economics and public policy, 12, 1-26.

Bundorf, M. K., Chun, N., Goda, G. S. and Kessler, D. P. (2009). Do markets respond to quality information? The case of fertility clinics. Journal of Health Economics, 28 (3), 718-727.

Bünnings, C., Schmitz, H., Tauchmann, H. and Ziebarth, N. R. (2017). The Role of Prices Relative to Supplemental Benefits and Service Quality in Health Plan Choice. Journal of Risk and Insurance, ((forthcoming)).

Busse, R. (2008). The Health System in Germany. Eurohealth - Health system snapshots: perspectives from six countries, 14 (1), 5-6.

— and Blümel, M. (2014). Germany: Health system review. European Observatory on Health Systems and Policies. Health Systems in Transition, 16 (2), 1-296. 
-, Nimptsch, U. and Mansky, T. (2009). Measuring, Monitoring, and Managing Quality in Germany's hospitals. Health Affairs, 28 (2), w294w304.

Cameron, A. C. and Trivedi, P. K. (2005). Microeconometrics: methods and applications. Cambridge University Press.

Chernew, M., Gowrisankaran, G. and P.Scanlon, D. (2008). Learning and the value of information: Evidence from health plan report cards. Journal of Econometrics, 144 (1), 156-174.

Cutler, D. M., Huckman, R. S. and Landrum, M. B. (2004). The Role of Information in Medical Market: An Analysis of Publicly Reported Outcomes in Cardiac Surgery. American Economic Review, 94 (2), 342-346.

Deutschen Gesellschaft Für Gynäkologie und Geburtshilfe (DGGG) (1995). Mindestanforderungen an prozessuale, strukturelle und organisatorische Voraussetzungen für geburtshilfliche Abteilungen. Der Frauenartzt, 36 (1), 27-28.

Dranove, D. and SfekAs, A. (2008). Start spreading the news: A structural estimate of the effects of New York hospital report cards. Journal of Health Economics, 27 (5), 1201-1207.

Elixhauser, A., Steiner, C., Harris, D. R. and Coffey, R. (1998). Comorbidity Measures for Use with Administrative Data. Medical Care, 36 (1), 8-27.

Gaynor, M. (2006). What Do We Know about Competition and Quality in Health Care Markets? Foundations and Trends in Microeconomics, 2 (6).

-, Propper, C. and Seiler, S. (2016). Free to choose? Reform, Choice, and Consideration Sets in the English National Health Service. American Economic Review, 106 (11), 3521-3557.

German Federal Statistical Office (Destatis) (2018). Gesundheit: Grunddaten der Krankenhäuser, 2017. Fachserie 12, reihe 6.1.1, German Federal Statistical Office (Statistisches Bundesamt), Wiesbaden.

Gutacker, N., Siciliani, L., Moscelli, G. and Gravelle, H. (2016). Choice of hospital: Which type of quality matters? Journal of Health Economics, 50, 230-246.

Hentschker, C. and Mennicken, R. (2015). The Volume-Outcome Relationship and Minimum Volume Standards - Empirical Evidence for Germany. Health Economics, 24 (6), 644-658.

- and - (2018). The Volume-Outcome Relationship Revisited: Practice Indeed Makes Perfect. Health Services Research, 53 (1), 15-34. 
HodGKin, D. (1996). Specialized service offerings and patients' choice of hospital: The case of cardiac catheterization. Journal of Health Economics, 15 (3), 305-332.

Huber, S. and Rust, C. (2016). Calculate Travel Time and Distance with OpenStreetMap Data using the Open Source Routing Machine (OSRM). The Stata Journal, 16 (2), 416-423.

Jin, G. Z. and Sorensen, A. T. (2006). Information and Consumer Choice: The Value of Publicized Health Plan Ratings. Journal of Health Economics, 25 (2), 248-275.

Jomeen, J. and Martin, C. R. (2008). The impact of choice of maternity care on psychological health outcomes for women during pregnancy and the postnatal period. Journal of Evaluation in Clinical Practice, 14 (3), 391-398.

Jung, K., Feldman, R. and Scanlon, D. (2011). Where would you go for your next hospitalization? Journal of Health Economics, 30 (4), 832-841.

Karmann, A. and Roesel, F. (2017). Hospital Policy and Productivity Evidence from German States. Health Economics, 26 (12), 1548-1565.

Mennicken, R., Kolodziej, I. W., Augurzky, B. and Kreienberg, R. (2014). Concentration of gynaecology and obstetrics in Germany: Is comprehensive access at stake? Health Policy, 118 (3), 396-406.

Moscelli, G., Siciliani, L., Gutacker, N. and Gravelle, H. (2016). Location, quality and choice of hospital: Evidence from England 2002-2013. Regional Science and Urban Economics, 60, 112-124.

Moscone, F., Tosetti, E. and Vittadini, G. (2012). Social Interaction in Patients' Hospital Choice: Evidences from Italy. Journal of the Royal Statistical Society Series A, 175 (2), 453-472.

Mukamel, D. B. and Mushlin, A. I. (1998). Quality of Care Information Makes a Difference: An Analysis of Market Share and Price Changes After Publication of the New York State Cardiac Surgery Mortality Reports. Medical Care, 36 (7), 945-954.

O'Cathain, A., Thomas, K., Walters, S. J., Nicholl, J. and Kirkham, M. (2002). Women's perceptions of informed choice in maternity care. Midwifery, 18 (2), 136-144.

Pilny, A. (2017). Explaining Differentials in Subsidy Levels Among Hospital Ownership Types in Germany. Health Economics, 26 (5), 566-581. 
- and Mennicken, R. (2014). Does Hospital Reputation Influence the Choice of Hospital? Ruhr Economic Papers No. 516, RWI-Leibniz-Institut für Wirtschaftsforschung, Ruhr-University Bochum, TU Dortmund University, University of Duisburg-Essen.

—, WüBkeR, A. and Ziebarth, N. R. (2017). Introducing risk adjustment and free health plan choice in employer-based health insurance: Evidence from Germany. Journal of Health Economics, 56, 330-351.

Pope, D. G. (2009). Reacting to rankings: Evidence from "America's Best Hospitals". Journal of Health Economics, 28 (6), 1154-1165.

Porell, F. W. and Adams, E. K. (1995). Hospital Choice Models: A Review and Assessment of their Utility for Policy Impact Analysis. Medical Care Research and Review, 52 (2), 158-195.

Propper, C. (2018). Competition in health care: lessons from the English experience. Health Economics, Policy and Law, 13 (Special Issue 3-4), 492508.

Pross, C., Averdunk, L.-H., Stjepanovic, J., Busse, R. and Geissler, A. (2017). Health care public reporting utilization-user clusters, web trails, and usage barriers on Germany's public reporting portal Weisse-Liste.de. BMC Medical Informatics And Decision Making, 17:48.

Quan, H., Sundararajan, V., Halfon, P., Fong, A., Burnand, B., Luthi, J.-C., Saunders, L. D., Beck, C. A., Feasby, T. E. and Ghali, W. A. (2005). Coding Algorithms for Defining Comorbidities in ICD-9-CM and ICD-10 Administrative Data. Medical Care, 43 (11), 11301139 .

Santos, R., Gravelle, H. and Propper, C. (2016). Does Quality Affect Patients' Choice of Doctor? Evidence from England. The Economic Journal, 127 (600), 445-494.

Scanlon, D. P., Chernew, M., Mclaughlin, C. and Solon, G. (2002). The impact of health plan report cards on managed care enrollment. Journal of Health Economics, 21 (1), 19-41.

Süddeutsche Zeitung (2017). Eine schöne Geburt? Ist nicht das Wichtigste. Retreived from: https://www.sueddeutsche.de/leben/hebammen-eineschoene-geburt-ist-nicht-das-wichtigste-1.3682528 [accessed 09.04.2019].

Sivey, P. (2012). The effect of waiting time and distance on hospital choice for English cataract patients. Health Economics, 21 (4), 444-456.

TAY, A. (2003). Assessing Competition in Hospital Care Markets: The Importance of Accounting for Quality Differentiation. The RAND Journal of Economics, 34 (4), 786-814. 
Techniker Krankenkasse (2010). Qualitätstransparenz im Krankenhaus: TK-Krankenhausbefragung. Tech. rep., Techniker Krankenkasse.

Varkevisser, M., van der Geest, S. A. and Schut, F. T. (2012). Do patients choose hospitals with high quality ratings? Empirical evidence from the market for angioplasty in the Netherlands. Journal of Health Economics, 31 (2), 371-378.

Wagle, R. R., Sabroe, S. and Nielsen, B. B. (2004). Socioeconomic and physical distance to the maternity hospital as predictors for place of delivery: an observation study from Nepal. BMC Pregnancy and Childbirth, $4(8)$.

Wasem, J., Gress, S. and Okma, K. G. (2004). The role of private health insurance in social health insurance countries. In R. B. Saltman, R. Busse and J. Figueras (eds.), Social health insurance systems in western Europe, New York: World Health Organization on behalf of the European Observatory on Health Systems and Policies, pp. 227-247.

Wedig, G. J. and Tai-Seale, M. (2002). The effect of report cards in consumer choice in the health insurance market. Journal of Health Economics, 21 (6), 1031-1048.

Werner, R. M., Norton, E. C., Konetzka, R. and Polsky, D. (2012). Do consumers respond to publicly reported quality information? Evidence from nursing homes. Journal of Health Economics, 31 (1), 50-61. 


\section{Tables and Figures}

FIGURE 1.

Distribution of objective quality (OQ) indicators
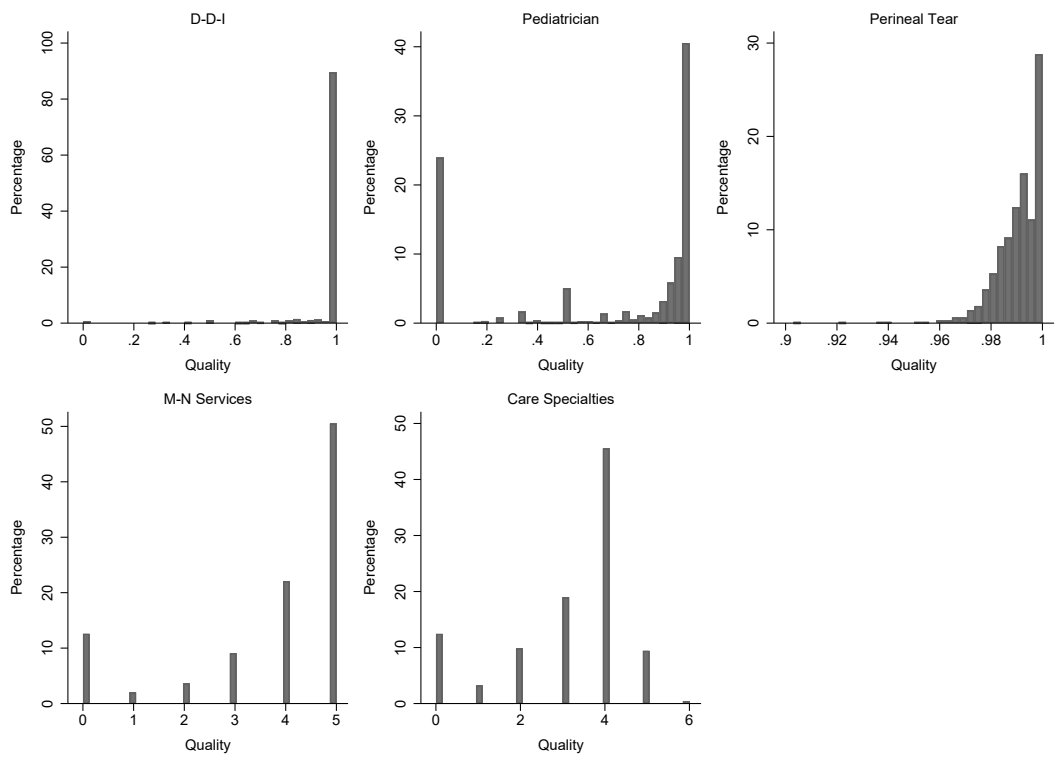

Note. - Empirical distributions of the objective quality (OQ) indicators (see section 3.2). The distributions of D-D-I, Pediatrician and Perineal Tear refer to shares between zero and one while the distributions of M-N Services and Care Specialties refer to discrete values between zero and five and six, respectively. 
FigURE 2.

Distribution of subjective quality (SQ) indicators
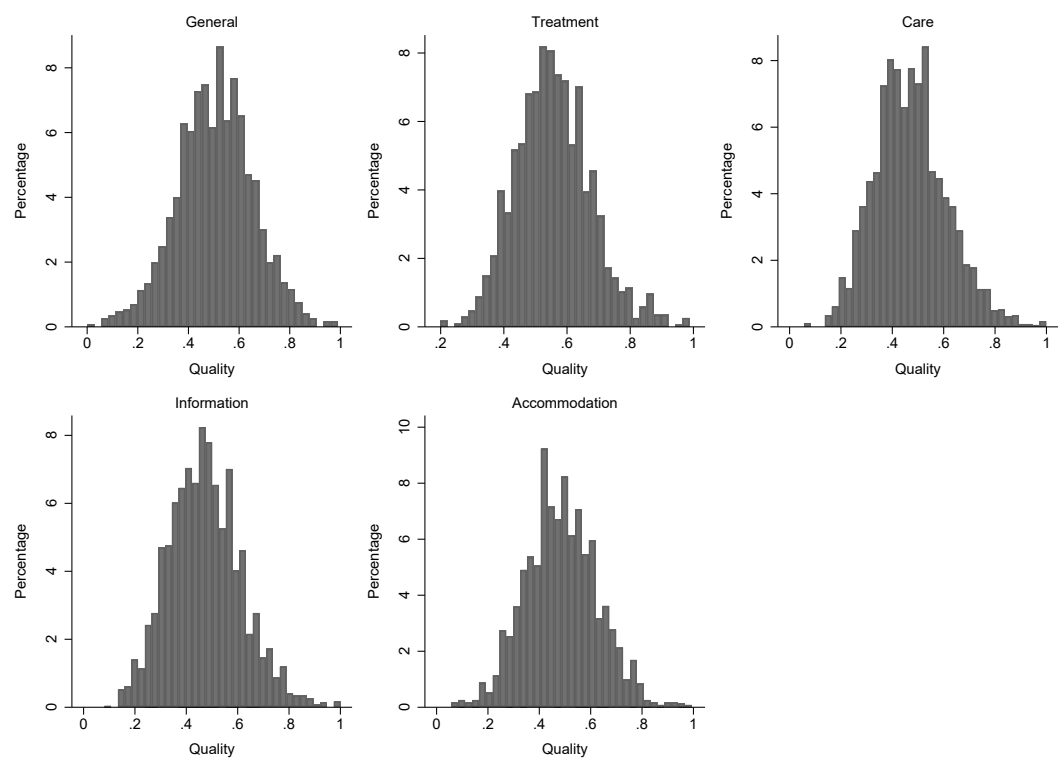

Note. - Empirical distributions of the subjective quality (SQ) indicators (see section 3.2). The distributions refers to (rescaled) shares of patients in the Techniker Krankenkasse (TK) survey who were satisfied with the overall, treatment, care, information and accommodation of their last hospital visit, respectively. 


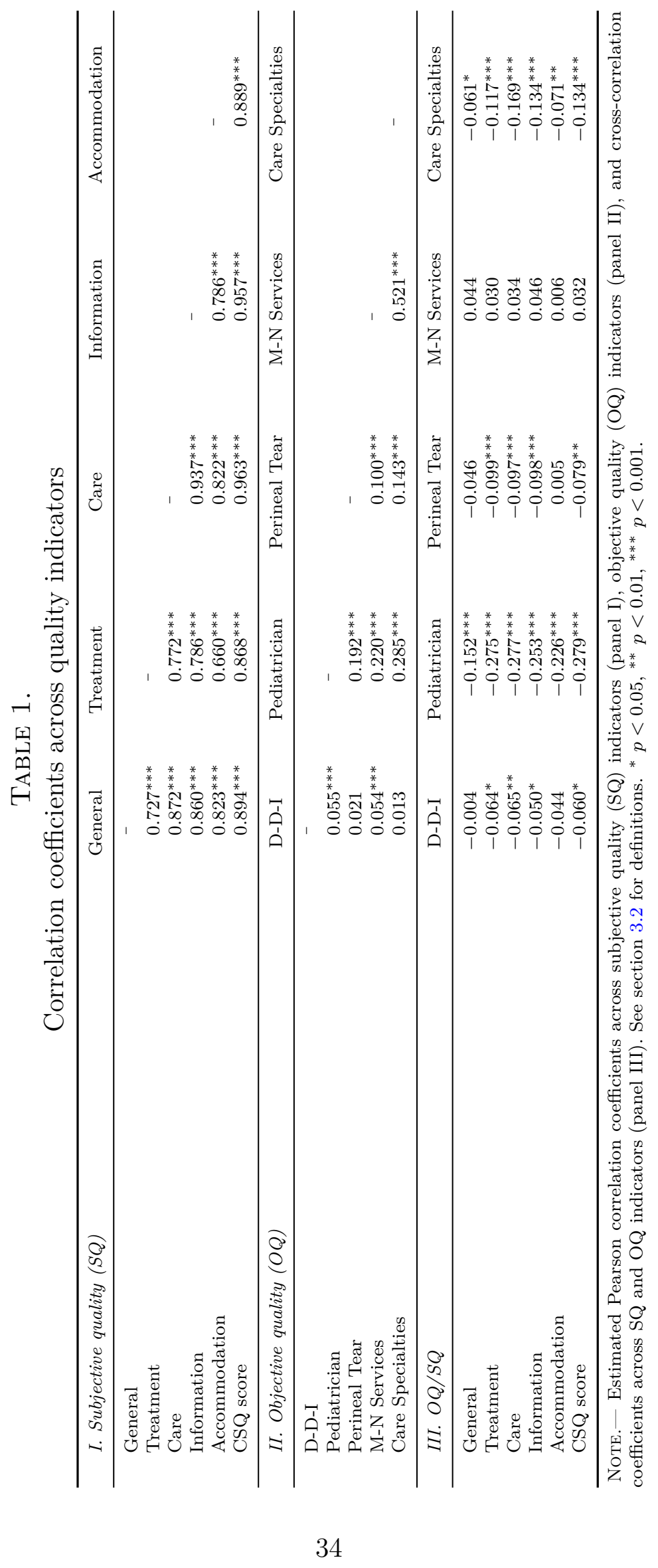




\section{FIGURE 3.}

Distribution of the composite subjective quality (CSQ)

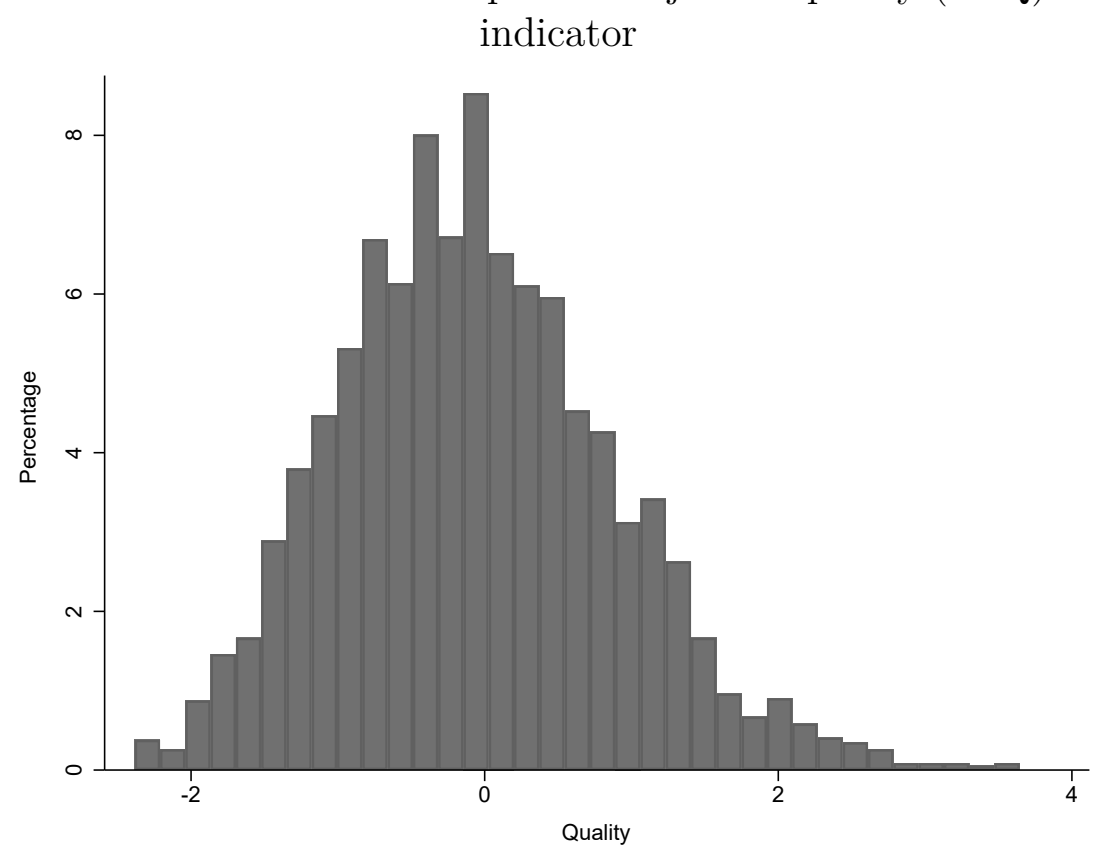

Note.- Empirical distribution of the composite subjective quality (CSQ) indicator (see section 3.2). The CSQ is constructed by application of principal component analysis (PCA) on the five satisfaction categories of the Techniker Krankenkasse (TK) patient satisfaction survey (see Figure 2).

\section{FiguRE 4.}

Distribution of patient choice of maternity clinic:

Distance and excess distance
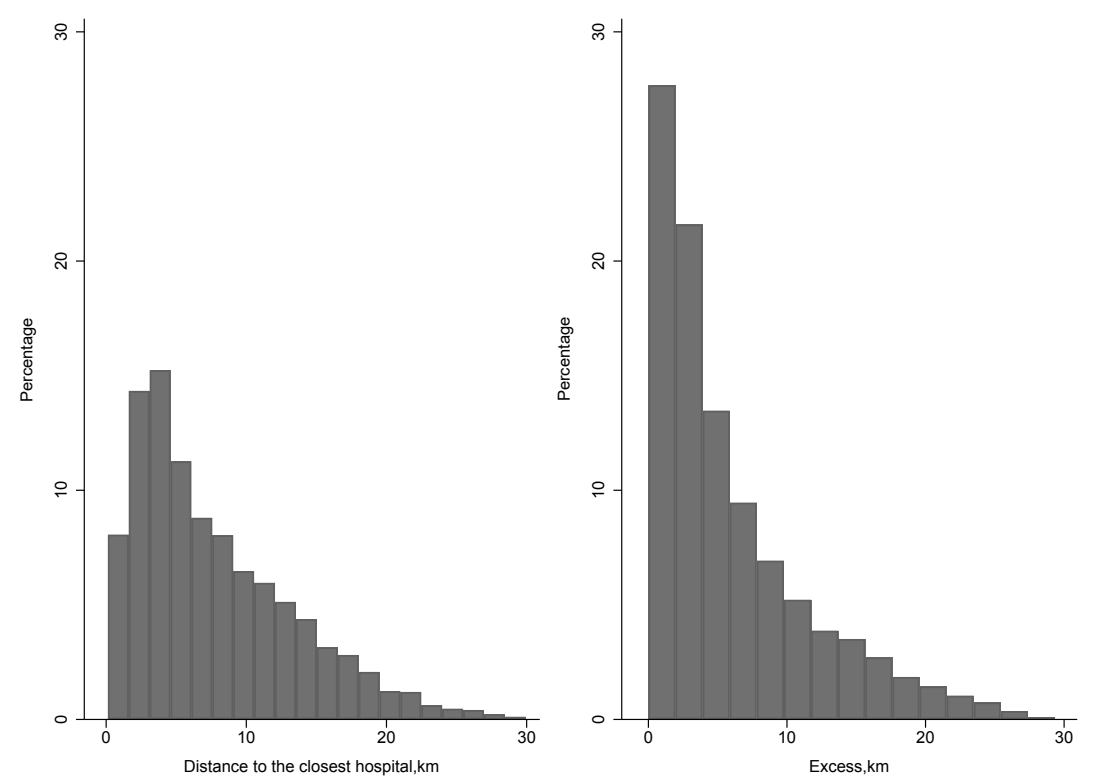

Note.- Empirical distribution of the distance to the closest hospital (left panel) and the excess distance between the closest and the chosen hospital (right panel) in a patient's choice set. 


\section{FigURE 5.}

Distribution of patient choice of maternity clinic: Hospital distance rank

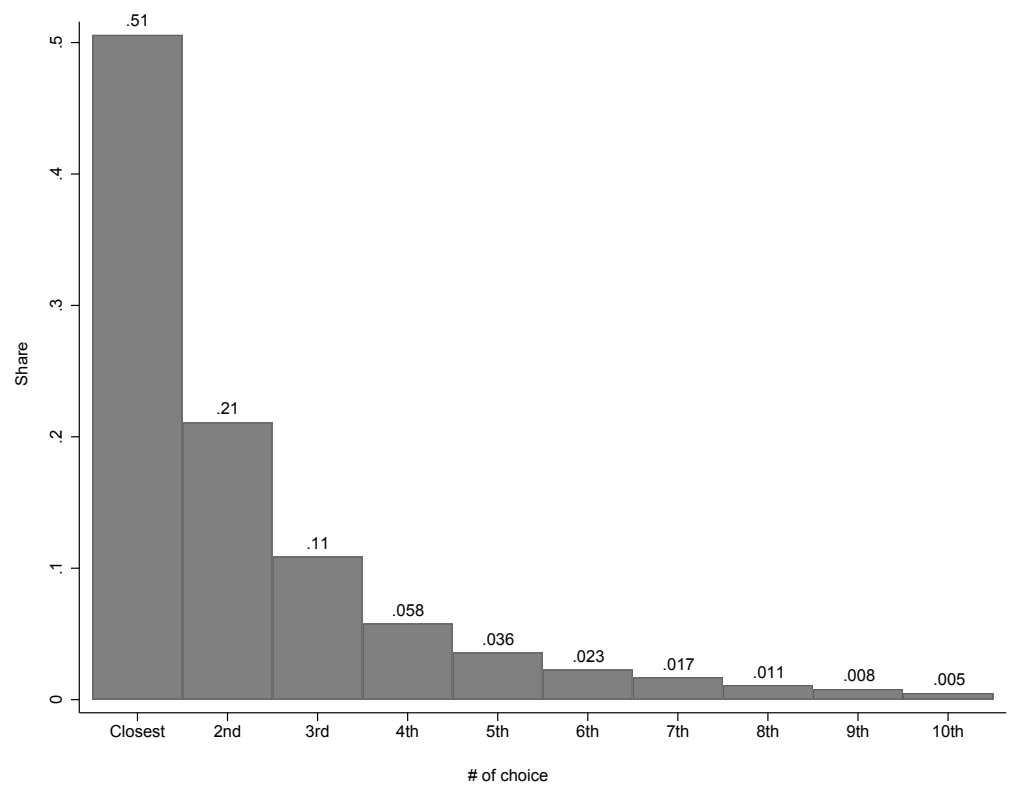

NotE.- Empirical distribution of patient choice of hospital ranked by distance from patient residence (indicated from left/closer to right/farther).

FigURE 6.

Geographical distribution of maternity clinics in Germany
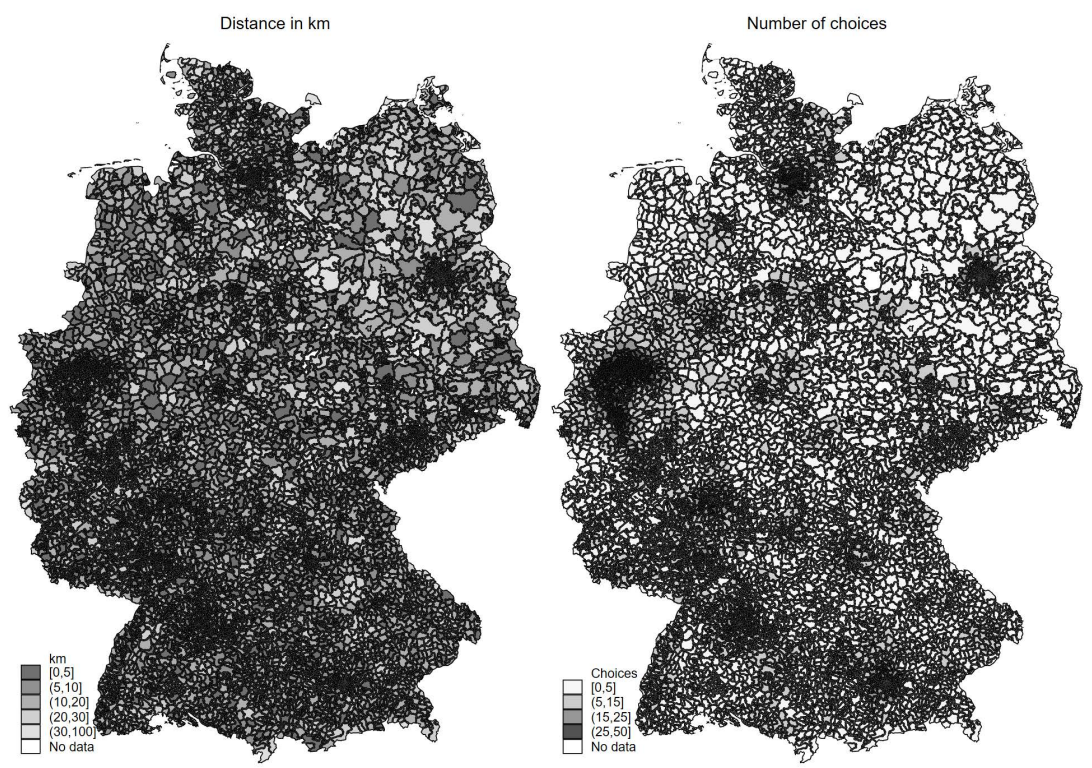

Note.- Distance in $\mathrm{km}$ to the closest hospital with a maternity clinic (left panel) and number of clinics within a 30 kilometers radius (right panel) by postal code. 
FiguRE 7.

Distribution of patient choice of maternity clinic: Hospital quality rank
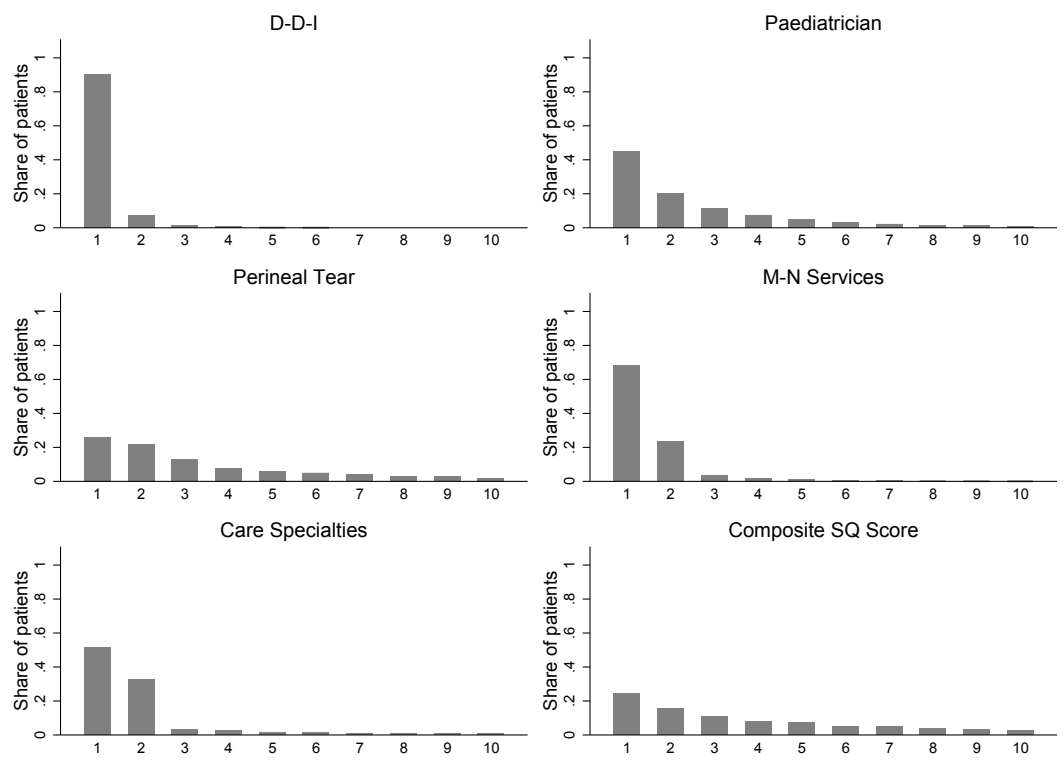

Note.- Shares of patients who chose the hospital with the best (1) to the worst (10) quality rating in their choice set by quality indicator (see section 3.2). 
TABLE 2 .

Descriptive sample statistics

\begin{tabular}{|c|c|c|c|c|}
\hline & \multicolumn{2}{|c|}{ Patient } & \multicolumn{2}{|c|}{ Choice-set } \\
\hline & Mean & SD & Mean & SD \\
\hline \multicolumn{5}{|l|}{ Patient characteristics } \\
\hline Age in years & 31.16 & [5.05] & 31.26 & [2.14] \\
\hline \# Elixhauser conditions & 0.17 & {$[0.41]$} & 0.15 & {$[0.17]$} \\
\hline If emergency & 0.30 & {$[0.46]$} & 0.29 & {$[0.29]$} \\
\hline If weekend & 0.23 & {$[0.42]$} & 0.23 & {$[0.16]$} \\
\hline If rush hour & 0.37 & {$[0.48]$} & 0.37 & {$[0.18]$} \\
\hline If risky & 0.04 & {$[0.21]$} & 0.04 & [0.08] \\
\hline \multicolumn{5}{|l|}{ Choice-set characteristics } \\
\hline If urban postal code & 0.76 & {$[0.43]$} & 0.72 & {$[0.45]$} \\
\hline If closest hospital chosen & 0.51 & {$[0.50]$} & 0.48 & {$[0.35]$} \\
\hline Excess distance & 2.95 & {$[4.97]$} & 3.29 & {$[3.45]$} \\
\hline Distance closest hospital (km) & 7.81 & {$[5.66]$} & 9.80 & [6.15] \\
\hline Travel time closest hospital (min) & 11.54 & {$[7.11]$} & 13.32 & {$[7.51]$} \\
\hline Distance chosen hospital $(\mathrm{km})$ & 10.76 & [7.36] & 13.09 & [6.70] \\
\hline Travel time chosen hospital (min) & 14.32 & {$[8.14]$} & 16.33 & [7.63] \\
\hline \multirow[t]{3}{*}{ Observations } & \multicolumn{2}{|c|}{225,352} & \multicolumn{2}{|c|}{8,666} \\
\hline & \multicolumn{2}{|c|}{ Hospital } & \multicolumn{2}{|c|}{ Closest hospital } \\
\hline & Mean & SD & Mean & $\mathrm{SD}$ \\
\hline \multicolumn{5}{|l|}{ Objective quality indicators $(O Q)$} \\
\hline D-D-I & 0.99 & {$[0.08]$} & 0.98 & {$[0.08]$} \\
\hline Pediatrician & 0.32 & {$[0.44]$} & 0.48 & {$[0.44]$} \\
\hline Perineal Tear & 0.99 & {$[0.01]$} & 0.96 & {$[0.07]$} \\
\hline M-N Services & 3.78 & [1.70] & 3.94 & {$[1.56]$} \\
\hline Care Specialties & 3.04 & {$[1.46]$} & 3.22 & {$[1.39]$} \\
\hline \multicolumn{5}{|l|}{ Subjective quality indicators (SQ) } \\
\hline General & 0.26 & {$[0.27]$} & 0.33 & {$[0.25]$} \\
\hline Treatment & 0.29 & {$[0.29]$} & 0.37 & {$[0.26]$} \\
\hline Care & 0.25 & {$[0.26]$} & 0.31 & {$[0.23]$} \\
\hline Information & 0.25 & {$[0.26]$} & 0.31 & {$[0.23]$} \\
\hline Accommodation & 0.25 & {$[0.26]$} & 0.32 & {$[0.23]$} \\
\hline Composite SQ Score & -0.03 & {$[0.68]$} & -0.06 & {$[0.72]$} \\
\hline \multicolumn{5}{|l|}{ Hospital characteristics } \\
\hline If public & 0.42 & {$[0.49]$} & 0.40 & {$[0.49]$} \\
\hline If private & 0.17 & {$[0.37]$} & 0.44 & {$[0.50]$} \\
\hline If university & 0.03 & {$[0.17]$} & 0.03 & {$[0.16]$} \\
\hline If teaching & 0.40 & {$[0.49]$} & 0.52 & {$[0.50]$} \\
\hline Birth-staff ratio & 176.72 & [136.88] & 192.92 & [136.14] \\
\hline Share specialized physicians & 0.56 & {$[0.16]$} & 0.41 & {$[0.27]$} \\
\hline \# hospital beds & 389.95 & [345.94] & 403.85 & [345.59] \\
\hline \# hospital midwives & 8.03 & {$[7.82]$} & 9.26 & {$[8.59]^{\circ}$} \\
\hline \# hospital nurses & 3.34 & {$[5.84]$} & 3.82 & {$[5.05]$} \\
\hline Observations & \multicolumn{2}{|c|}{6,545} & \multicolumn{2}{|c|}{8,666} \\
\hline
\end{tabular}

Note.- Descriptive statistics for different levels of data aggregation. Characteristics on the patient level (top-left), choice-set level (top-right), hospital level (bottom-left) and on closest hospital level (bottom-right). Emergency, rush hour and risky are dummy variables indicating whether a patient was admitted as an emergency case, whether admitted between 6am-10am on weekdays, and whether the patient was diagnosed with an secondary ICD-10 code of Z.35 (supervision of high-risk pregnancy), respectively. Excess distance is defined as the additional distance (in kilometers) between the closest and the chosen hospital. The Composite SQ score is constructed by application of principal component analysis (PCA) based on 5 satisfaction variables (see section 3.2). 
TABLE 3 .

Linear probability model estimates for choosing the closest hospital: Main results

\begin{tabular}{|c|c|c|c|}
\hline & (1) & $(2)$ & (3) \\
\hline Distance & $\begin{array}{c}-0.030 * * * \\
(-5.51)\end{array}$ & $\begin{array}{c}-0.031 * * * \\
(-5.58)\end{array}$ & $\begin{array}{c}-0.032 * * * \\
(-6.89)\end{array}$ \\
\hline Distance $^{2}$ & $\begin{array}{c}0.001^{*} \\
(2.20)\end{array}$ & $\begin{array}{c}0.001^{*} \\
(2.38)\end{array}$ & $\begin{array}{c}0.001^{* *} \\
(2.91)\end{array}$ \\
\hline Distance $^{3}$ & $\begin{array}{l}-0.000 \\
(-1.36)\end{array}$ & $\begin{array}{l}-0.000 \\
(-1.58)\end{array}$ & $\begin{array}{c}-0.000^{*} \\
(-2.07)\end{array}$ \\
\hline D-D-I & $\begin{array}{l}0.033 \\
(0.65)\end{array}$ & $\begin{array}{l}0.049 \\
(0.88)\end{array}$ & $\begin{array}{c}0.150^{* *} \\
(3.24)\end{array}$ \\
\hline Pediatrician & $\begin{array}{c}0.061^{* * *} \\
(4.10)\end{array}$ & $\begin{array}{c}0.070^{* * *} * \\
(4.59)\end{array}$ & $\begin{array}{c}0.072^{* * *} \\
(5.43)\end{array}$ \\
\hline Perineal Tear & $\begin{array}{l}0.051 \\
(0.52)\end{array}$ & $\begin{array}{l}0.085 \\
(0.81)\end{array}$ & $\begin{array}{l}0.032 \\
(0.41)\end{array}$ \\
\hline M-N Services & $\begin{array}{c}0.031^{* * *} \\
(4.98)\end{array}$ & $\begin{array}{c}0.030 * * * \\
(4.88)\end{array}$ & $\begin{array}{c}0.026^{* * *} \\
(4.58)\end{array}$ \\
\hline Care Specialties & $\begin{array}{l}0.010 \\
(1.78)\end{array}$ & $\begin{array}{c}0.013^{*} \\
(2.31)\end{array}$ & $\begin{array}{l}0.002 \\
(0.46)\end{array}$ \\
\hline General & $\begin{array}{l}-0.021 \\
(-0.14)\end{array}$ & & \\
\hline Treatment & $\begin{array}{l}-0.041 \\
(-0.35)\end{array}$ & & \\
\hline Care & $\begin{array}{l}-0.226 \\
(-1.19)\end{array}$ & & \\
\hline Information & $\begin{array}{l}-0.096 \\
(-0.53)\end{array}$ & & \\
\hline Accommodation & $\begin{array}{c}0.340^{* *} \\
(2.75)\end{array}$ & & \\
\hline Composite SQ score & & $\begin{array}{l}-0.003 \\
(-0.61)\end{array}$ & $\begin{array}{l}0.013^{*} \\
(2.34)\end{array}$ \\
\hline Patient characteristics & Yes & Yes & Yes \\
\hline Hospital characteristics & Yes & Yes & Yes \\
\hline Hospital fixed effects & No & No & Yes \\
\hline Observations & 225,352 & 225,352 & 225,352 \\
\hline
\end{tabular}

NOTE. - Linear probability model (LPM) estimates for whether a patient chose the closest hospital in her choice set. Patient characteristics include age, \# of Elixhauser conditions, whether a patient was admitted as an emergency case, on a weekend, between 6am-10am on weekdays, and whether the patient was admitted with an secondary ICD-10 code of Z.35 (supervision of high-risk pregnancy). Hospital characteristics include ownership type, \# of beds, if university, if teaching, \# of midwives; Birth-Staff ratio (\# of cases per doctor); share specialized doctors (\# of specialized doctors as a share of all doctors); \# of nurses and an indicator for whether subjective quality was missing. Composite SQ score is based on five satisfaction variables: General, Treatment, Care, Communication, Accommodation. Standard errors are clustered on spatial planning regions (96 clusters). $t$-statistics in parentheses; ${ }^{*} p<0.05$, ${ }^{* *} p<0.01,{ }^{* * *} p<0.001$. 
TABLE 4.

Conditional logit model estimates for choice of hospital: Main results

\begin{tabular}{|c|c|c|c|}
\hline & (1) & (2) & (3) \\
\hline Distance & $\begin{array}{c}-0.289^{* * *} \\
(-13.81)\end{array}$ & $\begin{array}{c}-0.284^{* * * *} \\
(-14.35)\end{array}$ & $\begin{array}{c}-0.299^{* * *} \\
(-14.53)\end{array}$ \\
\hline Distance $^{2}$ & $\begin{array}{c}0.004^{* *} \\
(3.21)\end{array}$ & $\begin{array}{c}0.004^{* *} \\
(3.29)\end{array}$ & $\begin{array}{c}0.003^{*} \\
(2.47)\end{array}$ \\
\hline Distance $^{3}$ & $\begin{array}{l}-0.000 \\
(-1.37)\end{array}$ & $\begin{array}{l}-0.000 \\
(-1.39)\end{array}$ & $\begin{array}{l}-0.000 \\
(-0.30)\end{array}$ \\
\hline D-D-I & $\begin{array}{c}0.534^{* *} \\
(2.60)\end{array}$ & $\begin{array}{c}0.551^{*} \\
(2.19)\end{array}$ & $\begin{array}{l}0.150 \\
(0.76)\end{array}$ \\
\hline Pediatrician & $\begin{array}{c}0.305^{* * * *} \\
(5.58)\end{array}$ & $\begin{array}{c}0.354^{* * * *} \\
(5.28)\end{array}$ & $\begin{array}{l}0.067 \\
(0.90)\end{array}$ \\
\hline Perineal Tear & $\begin{array}{l}0.270 \\
(0.72)\end{array}$ & $\begin{array}{c}0.604 \\
(1.46)\end{array}$ & $\begin{array}{c}0.493 \\
(1.70)\end{array}$ \\
\hline M-N-Services & $\begin{array}{c}0.217^{* * *} \\
(8.69)\end{array}$ & $\begin{array}{c}0.216^{* * *} \\
(8.99)\end{array}$ & $\begin{array}{c}0.384^{* * *} \\
(4.52)\end{array}$ \\
\hline Care Specialties & $\begin{array}{c}0.070^{* *} \\
(3.08)\end{array}$ & $\begin{array}{c}0.081^{* *} \\
(3.21)\end{array}$ & $\begin{array}{c}0.153^{* *} \\
(2.72)\end{array}$ \\
\hline General & $\begin{array}{c}10.21^{* * *} \\
(7.72)\end{array}$ & & \\
\hline Treatment & $\begin{array}{l}-0.676 \\
(-0.53)\end{array}$ & & \\
\hline Care & $\begin{array}{l}-6.457^{*} \\
(-2.40)\end{array}$ & & \\
\hline Information & $\begin{array}{l}0.800 \\
(0.34)\end{array}$ & & \\
\hline Accommodation & $\begin{array}{c}-3.537^{* *} \\
(-2.72)\end{array}$ & & \\
\hline Composite SQ score & & $\begin{array}{c}0.071^{* * *} \\
(4.35)\end{array}$ & $\begin{array}{l}0.017 \\
(0.62)\end{array}$ \\
\hline Patient characteristics & Yes & Yes & Yes \\
\hline Hospital characteristics & Yes & Yes & Yes \\
\hline Hospital fixed effects & No & No & Yes \\
\hline Observations & $2,191,422$ & $2,191,422$ & $2,191,422$ \\
\hline
\end{tabular}

Note.- Conditional logit estimates for patient choice of hospital. Patient characteristics include age, \# of Elixhauser conditions, whether a patient was admitted as an emergency case, on a weekend, between $6 \mathrm{am}-10 \mathrm{am}$ on weekdays, and whether the patient was admitted with an secondary ICD-10 code of Z.35 (supervision of high-risk pregnancy). Hospital characteristics include ownership type, \# of beds, if university, if teaching, \# of midwives; Birth-Staff ratio (\# of cases per doctor); share specialized doctors (\# of specialized doctors as a share of all doctors); \# of nurses and an indicator for whether subjective quality was missing. Composite SQ score is based on five satisfaction variables: General, Treatment, Care, Communication, Accommodation. Standard errors are clustered on spatial planning regions (96 clusters). $t$-statistics in parentheses; ${ }^{*} p<0.05,{ }^{* *} p<0.01,{ }^{* * *} p<0.001$. 
FiguRE 8.

Willingness-to-travel (WTT) estimates excluding hospital fixed effects

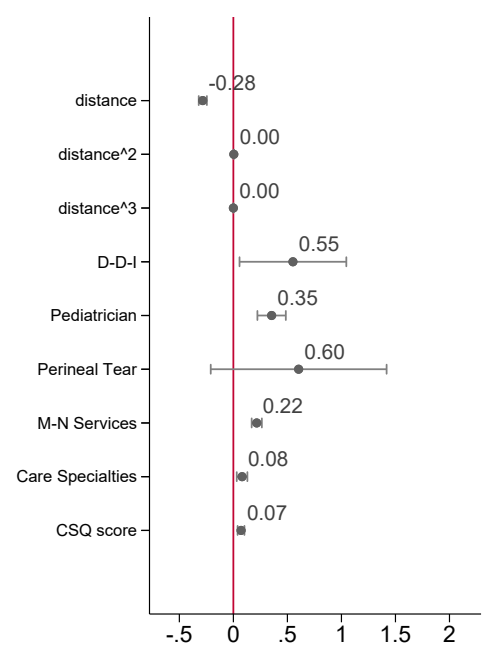

- $951 \%$ Confidence Interval

- conditional logit coefficient estimat

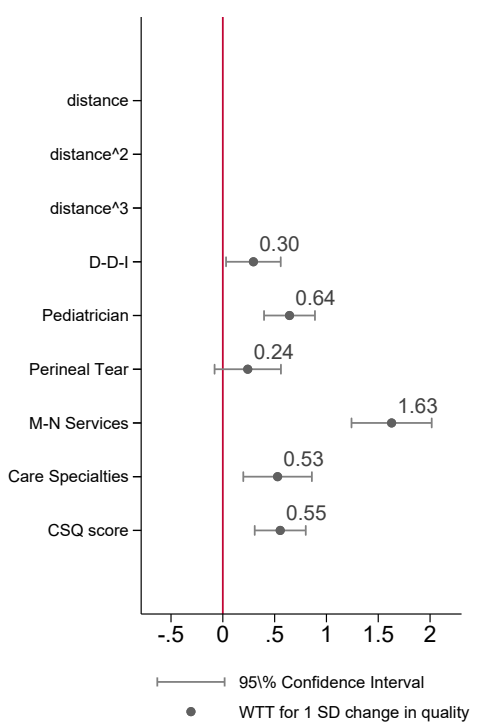

Note.- Conditional logit estimates coefficients (left panel) and willingness-totravel (WTT) estimates (right panel) excluding hospital fixed effects. WTT estimates are obtained from equation 12 using parameter estimates from the conditional logit model as inputs.

\section{FiguRE 9.}

Willingness-to-travel (WTT) estimates including hospital fixed effects
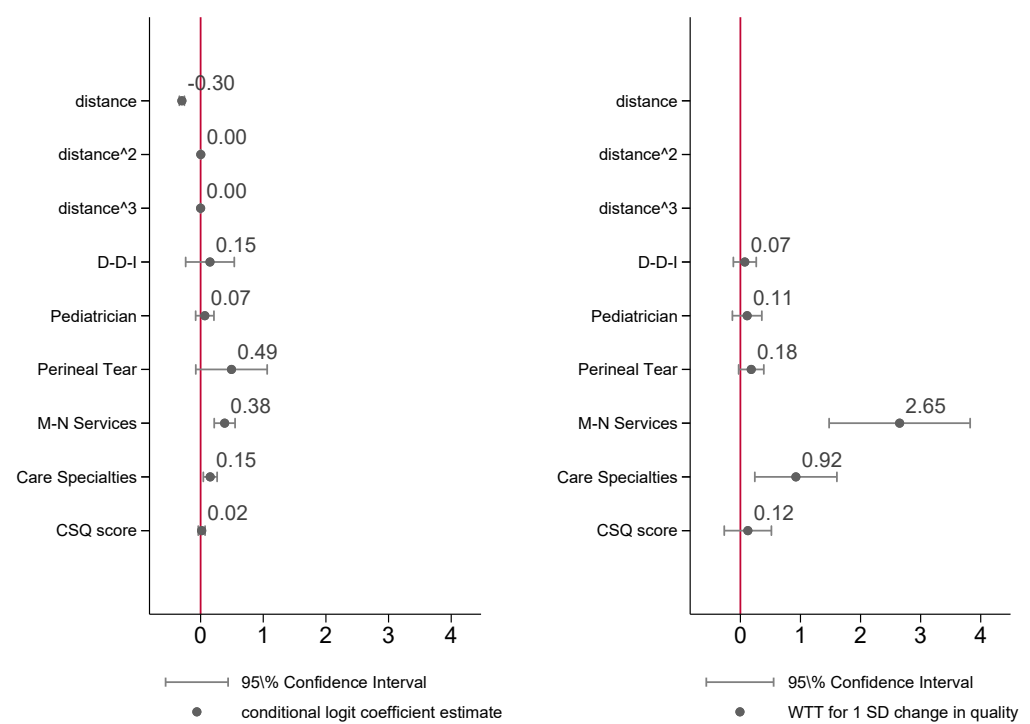

Note.- Conditional logit estimates coefficients (left panel) and willingness-totravel (WTT) estimates (right panel) including hospital fixed effects. WTT estimates are obtained from equation 12 using parameter estimates from the conditional logit model as inputs. 
TABLE 5 .

Conditional logit model estimates for choice of hospital: Falsification test

\begin{tabular}{lcccc}
\hline & $(1)$ & $(2)$ & $(3)$ & $(4)$ \\
\hline Distance & $-0.287^{* * *}$ & $-0.324^{* * *}$ & $-0.286^{* * *}$ & $-0.316^{* * *}$ \\
& $(-13.34)$ & $(-15.25)$ & $(-13.34)$ & $(-14.63)$ \\
Distance $^{2}$ & $0.004^{* *}$ & $0.005^{* * *}$ & $0.004^{* *}$ & $0.004^{* * *}$ \\
& $(3.29)$ & $(3.94)$ & $(3.29)$ & $(3.30)$ \\
Distance $^{3}$ & -0.000 & -0.000 & -0.000 & -0.000 \\
& $(-1.60)$ & $(-1.69)$ & $(-1.60)$ & $(-1.08)$ \\
In-hospital AMI mortality & -0.119 & -0.046 & & \\
30-day AMI mortality & $(-0.62)$ & $(-0.28)$ & & \\
& & & -0.058 & 0.007 \\
Patient characteristics & & & $(-0.30)$ & $(0.04)$ \\
Hospital characteristics & Yes & Yes & Yes & Yes \\
Hospital fixed effects & No & Yes & Yes & Yes \\
\hline Observations & $2,191,422$ & $2,191,422$ & $2,191,422$ & $2,191,422$ \\
\hline
\end{tabular}

Note. - Conditional logit estimates for patient choice of hospital including in-hospital (columns 1-2) and 30-days post-discharge (columns 3-4) acute myocardial infarction (AMI) mortality as additional regressors. Patient characteristics include age, \# of Elixhauser conditions, whether a patient was admitted as an emergency case, on a weekend, between 6am-10am on weekdays, and whether the patient was admitted with an secondary ICD-10 code of Z.35 (supervision of high-risk pregnancy). Hospital characteristics include ownership type, \# of beds, if university, if teaching, \# of midwives; Birth-Staff ratio (\# of cases per doctor); share specialized doctors (\# of specialized doctors as a share of all doctors); \# of nurses and an indicator for whether subjective quality was missing. Composite SQ score is based on five satisfaction variables: General, Treatment, Care, Communication, Accommodation. Standard errors are clustered on spatial planning regions (96 clusters). $t$-statistics in parentheses; * $p<0.05,{ }^{* *} p<0.01,{ }^{* * *} p<0.001$. 


\section{TABLE 6.}

Conditional logit model estimates for choice of hospital: Heterogeneity analysis I

\begin{tabular}{|c|c|c|c|c|c|c|}
\hline & \multicolumn{4}{|c|}{ Choice set definition } & \multirow{2}{*}{\multicolumn{2}{|c|}{$\frac{\text { Travel time definition }}{25 \text { choices }}$}} \\
\hline & \multicolumn{2}{|c|}{15 choices } & \multicolumn{2}{|c|}{20 choices } & & \\
\hline & (1) & $(2)$ & (3) & $(4)$ & $(5)$ & (6) \\
\hline Distance & $\begin{array}{c}-0.284^{* * *} \\
(-14.30)\end{array}$ & $\begin{array}{c}-0.309^{* * *} \\
(-15.57)\end{array}$ & $\begin{array}{c}-0.284^{* * *} \\
(-14.36)\end{array}$ & $\begin{array}{c}-0.297^{* * *} \\
(-14.18)\end{array}$ & $\begin{array}{c}-0.177^{* * *} \\
(-7.77)\end{array}$ & $\begin{array}{c}-0.297^{* * *} \\
(-8.96)\end{array}$ \\
\hline Distance $^{2}$ & $\begin{array}{c}0.004^{* *} \\
(3.24)\end{array}$ & $\begin{array}{c}0.004^{* *} \\
(3.13)\end{array}$ & $\begin{array}{c}0.004^{* *} \\
(3.23)\end{array}$ & $\begin{array}{c}0.003^{*} \\
(2.46)\end{array}$ & $\begin{array}{c}-0.004^{*} \\
(-2.52)\end{array}$ & $\begin{array}{l}0.003 \\
(1.31)\end{array}$ \\
\hline Distance $^{3}$ & $\begin{array}{l}-0.000 \\
(-1.25)\end{array}$ & $\begin{array}{l}-0.000 \\
(-0.74)\end{array}$ & $\begin{array}{l}-0.000 \\
(-1.26)\end{array}$ & $\begin{array}{l}-0.000 \\
(-0.25)\end{array}$ & $\begin{array}{c}0.000^{* *} \\
(3.19)\end{array}$ & $\begin{array}{l}-0.000 \\
(-0.36)\end{array}$ \\
\hline D-D-I & $\begin{array}{c}0.555^{*} \\
(2.20)\end{array}$ & $\begin{array}{l}0.171 \\
(0.84)\end{array}$ & $\begin{array}{c}0.552^{*} \\
(2.19)\end{array}$ & $\begin{array}{l}0.171 \\
(0.88)\end{array}$ & $\begin{array}{l}0.555 \\
(1.91)\end{array}$ & $\begin{array}{l}0.171 \\
(1.01)\end{array}$ \\
\hline Pediatrician & $\begin{array}{c}0.350^{* * *} \\
(5.44)\end{array}$ & $\begin{array}{l}0.074 \\
(0.96)\end{array}$ & $\begin{array}{c}0.354^{* * *} \\
(5.31)\end{array}$ & $\begin{array}{l}0.068 \\
(0.94)\end{array}$ & $\begin{array}{c}0.328^{* * *} \\
(4.69)\end{array}$ & $\begin{array}{c}0.0427 \\
(0.70)\end{array}$ \\
\hline Perineal Tear & $\begin{array}{c}0.620 \\
(1.50)\end{array}$ & $\begin{array}{c}0.508 \\
(1.76)\end{array}$ & $\begin{array}{l}0.614 \\
(1.48)\end{array}$ & $\begin{array}{l}0.497 \\
(1.83)\end{array}$ & $\begin{array}{l}0.449 \\
(1.06)\end{array}$ & $\begin{array}{l}0.401 \\
(1.48)\end{array}$ \\
\hline M-N Services & $\begin{array}{c}0.217^{* * *} \\
(9.23)\end{array}$ & $\begin{array}{c}0.397^{* * *} \\
(4.45)\end{array}$ & $\begin{array}{c}0.217^{\text {*** }} \\
(9.02)\end{array}$ & $\begin{array}{c}0.369^{* * *} \\
(4.55)\end{array}$ & $\begin{array}{c}0.208^{* * *} \\
(8.13)\end{array}$ & $\begin{array}{c}0.175^{* * *} \\
(4.67)\end{array}$ \\
\hline Care Specialties & $\begin{array}{c}0.083^{* *} \\
(3.24)\end{array}$ & $\begin{array}{c}0.128^{*} \\
(2.48)\end{array}$ & $\begin{array}{c}0.081^{* *} \\
(3.23)\end{array}$ & $\begin{array}{c}0.115^{*} \\
(2.42)\end{array}$ & $\begin{array}{c}0.091^{* *} \\
(3.29)\end{array}$ & $\begin{array}{c}0.099^{* *} \\
(2.72)\end{array}$ \\
\hline Composite SQ score & $\begin{array}{c}0.066^{* * *} \\
(3.77)\end{array}$ & $\begin{array}{l}0.035 \\
(1.24)\end{array}$ & $\begin{array}{c}0.070^{* * *} \\
(4.34)\end{array}$ & $\begin{array}{l}0.038 \\
(1.35)\end{array}$ & $\begin{array}{c}0.057^{* *} \\
(3.28)\end{array}$ & $\begin{array}{l}0.001 \\
(0.03)\end{array}$ \\
\hline Patient characteristics & Yes & Yes & Yes & Yes & Yes & Yes \\
\hline Hospital characteristics & Yes & Yes & Yes & Yes & Yes & Yes \\
\hline Hospital fixed effects & No & Yes & No & Yes & No & Yes \\
\hline Observations & 1,91 & 9,790 & 2,118 & 8,517 & $2,1 \mathrm{~s}$ & 91,422 \\
\hline
\end{tabular}

Note. - Conditional logit estimates for patient choice of hospital varying baseline choice set and distance definitions. Columns (1)-(2) and (3)-(4) report results when choice sets have been restricted to a maximum of 15 and 20 choices, respectively. Columns (5)-(6) report results by replacing distance in kilometers by travel time in minutes by car. Patient characteristics include age, \# of Elixhauser conditions, whether a patient was admitted as an emergency case, on a weekend, between 6 am10 am on weekdays, and whether the patient was admitted with an secondary ICD-10 code of Z.35 (supervision of high-risk pregnancy). Hospital characteristics include ownership type, \# of beds, if university, if teaching, \# of midwives; Birth-Staff ratio (\# of cases per doctor); share specialized doctors (\# of specialized doctors as a share of all doctors); \# of nurses and an indicator for whether subjective quality was missing. Composite SQ score is based on five satisfaction variables: General, Treatment, Care, Communication, Accommodation. Standard errors are clustered on spatial planning regions (96 clusters). $t$-statistics in parentheses; ${ }^{*} p<0.05,{ }^{* *} p<0.01,{ }^{* * *} p<0.001$. 
TABLE 7.

Conditional logit model estimates for choice of hospital:

Heterogeneity analysis II

\begin{tabular}{|c|c|c|c|c|}
\hline & \multicolumn{2}{|c|}{$I$ : Emergency } & \multicolumn{2}{|c|}{$I:$ Urban } \\
\hline & (1) & $(2)$ & (3) & (4) \\
\hline Distance & $\begin{array}{c}-0.312^{* * *} \\
(-10.88)\end{array}$ & $\begin{array}{c}-0.356^{* * *} \\
(-13.59)\end{array}$ & $\begin{array}{c}-0.098^{* *} \\
(-2.78)\end{array}$ & $\begin{array}{c}-0.192^{* * *} \\
(-7.00)\end{array}$ \\
\hline Distance $\times I$ & $\begin{array}{l}-0.039 \\
(-1.13)\end{array}$ & $\begin{array}{l}-0.062 \\
(-1.62)\end{array}$ & $\begin{array}{c}-0.245^{* * *} \\
(-5.59)\end{array}$ & $\begin{array}{c}-0.198^{* * *} \\
(-5.42)\end{array}$ \\
\hline Distance $^{2}$ & $\begin{array}{c}0.005^{* *} \\
(2.89)\end{array}$ & $\begin{array}{c}0.007^{* * *} \\
(3.86)\end{array}$ & $\begin{array}{l}-0.004 \\
(-1.69)\end{array}$ & $\begin{array}{l}0.001 \\
(0.77)\end{array}$ \\
\hline Distance $^{2} \times I$ & $\begin{array}{l}0.002 \\
(0.84)\end{array}$ & $\begin{array}{l}0.005 \\
(1.77)\end{array}$ & $\begin{array}{c}0.011^{* * *} \\
(3.54)\end{array}$ & $\begin{array}{c}0.007^{* *} \\
(2.78)\end{array}$ \\
\hline Distance $^{3}$ & $\begin{array}{l}-0.000 \\
(-1.21)\end{array}$ & $\begin{array}{l}-0.000 \\
(-1.83)\end{array}$ & $\begin{array}{l}0.000 \\
(1.90)\end{array}$ & $\begin{array}{l}-0.000 \\
(-0.25)\end{array}$ \\
\hline Distance $^{3} \times I$ & $\begin{array}{l}-0.000 \\
(-0.74)\end{array}$ & $\begin{array}{l}-0.000 \\
(-1.85)\end{array}$ & $\begin{array}{c}-0.000^{* *} \\
(-2.67)\end{array}$ & $\begin{array}{l}-0.000 \\
(-1.73)\end{array}$ \\
\hline D-D-I & $\begin{array}{l}0.452 \\
(1.79)\end{array}$ & $\begin{array}{l}0.368 \\
(1.70)\end{array}$ & $\begin{array}{l}0.513 \\
(1.88)\end{array}$ & $\begin{array}{l}0.208 \\
(0.86)\end{array}$ \\
\hline D-D-I $\times I$ & $\begin{array}{l}0.391 \\
(1.36)\end{array}$ & $\begin{array}{l}0.034 \\
(0.11)\end{array}$ & $\begin{array}{l}-0.023 \\
(-0.11)\end{array}$ & $\begin{array}{l}0.240 \\
(1.39)\end{array}$ \\
\hline Pediatrician & $\begin{array}{c}0.318^{* *} \\
(3.28)\end{array}$ & $\begin{array}{l}-0.025 \\
(-0.22)\end{array}$ & $\begin{array}{c}0.326^{* *} \\
(3.02)\end{array}$ & $\begin{array}{l}0.058 \\
(0.40)\end{array}$ \\
\hline Paediatrician $\times I$ & $\begin{array}{l}0.053 \\
(0.29)\end{array}$ & $\begin{array}{l}0.097 \\
(0.42)\end{array}$ & $\begin{array}{l}0.015 \\
(0.13)\end{array}$ & $\begin{array}{l}0.010 \\
(0.08)\end{array}$ \\
\hline Perineal Tear & $\begin{array}{l}0.770 \\
(1.83)\end{array}$ & $\begin{array}{l}0.578 \\
(1.77)\end{array}$ & $\begin{array}{l}1.129^{*} \\
(2.37)\end{array}$ & $\begin{array}{l}0.552 \\
(1.37)\end{array}$ \\
\hline Perineal Tear $\times I$ & $\begin{array}{l}-0.525 \\
(-1.74)\end{array}$ & $\begin{array}{l}-0.054 \\
(-0.15)\end{array}$ & $\begin{array}{l}-0.718 \\
(-1.87)\end{array}$ & $\begin{array}{l}0.049 \\
(0.19)\end{array}$ \\
\hline M-N Services & $\begin{array}{c}0.233^{* * *} \\
(6.58)\end{array}$ & $\begin{array}{c}0.388^{* * *} \\
(4.06)\end{array}$ & $\begin{array}{c}0.240^{* * *} \\
(6.25)\end{array}$ & $\begin{array}{c}0.291^{* *} \\
(3.18)\end{array}$ \\
\hline M-N Services $\times I$ & $\begin{array}{l}-0.064 \\
(-1.14)\end{array}$ & $\begin{array}{l}-0.053 \\
(-0.75)\end{array}$ & $\begin{array}{l}-0.038 \\
(-0.83)\end{array}$ & $\begin{array}{l}0.085 \\
(1.40)\end{array}$ \\
\hline Care Specialties & $\begin{array}{l}0.041 \\
(1.12)\end{array}$ & $\begin{array}{l}0.032 \\
(0.55)\end{array}$ & $\begin{array}{l}0.064 \\
(1.50)\end{array}$ & $\begin{array}{l}0.018 \\
(0.32)\end{array}$ \\
\hline Care Specialties $\times I$ & $\begin{array}{l}0.084 \\
(1.31)\end{array}$ & $\begin{array}{l}0.107 \\
(1.33)\end{array}$ & $\begin{array}{l}0.011 \\
(0.26)\end{array}$ & $\begin{array}{l}0.058 \\
(1.23)\end{array}$ \\
\hline Composite SQ score & $\begin{array}{c}0.099^{* * *} \\
(3.72)\end{array}$ & $\begin{array}{l}0.056 \\
(1.64)\end{array}$ & $\begin{array}{l}0.060^{*} \\
(2.17)\end{array}$ & $\begin{array}{l}0.055 \\
(1.38)\end{array}$ \\
\hline Composite SQ score $\times I$ & $\begin{array}{l}-0.067 \\
(-1.32)\end{array}$ & $\begin{array}{l}-0.099 \\
(-1.54)\end{array}$ & $\begin{array}{l}0.020 \\
(0.79)\end{array}$ & $\begin{array}{l}-0.006 \\
(-0.24)\end{array}$ \\
\hline Patient characteristics & Yes & Yes & Yes & Yes \\
\hline Hospital characteristics & Yes & Yes & Yes & Yes \\
\hline Hospital fixed effects & No & Yes & No & Yes \\
\hline Observations & \multicolumn{2}{|c|}{$2,191,422$} & \multicolumn{2}{|c|}{$2,191,422$} \\
\hline
\end{tabular}

Note.- Conditional logit estimates for patient choice of hospital including interactions between emergency cases (columns 1-2) and patients living in urban areas (columns 3-4) as additional regressors, respectively. Patient characteristics include age, \# of Elixhauser conditions, whether a patient was admitted as an emergency case, on a weekend, between $6 \mathrm{am}-10 \mathrm{am}$ on weekdays, and whether the patient was admitted with an secondary ICD-10 code of Z.35 (supervision of high-risk pregnancy). Hospital characteristics include ownership type, \# of beds, if university, if teaching, \# of midwives; Birth-Staff ratio (\# of cases per doctor); share specialized doctors (\# of specialized doctors as a share of all doctors); \# of nurses and an indicator for whether subjective quality was missing. Composite SQ score is based on five satisfaction variables: General, Treatment, Care, Communication, Accommodation. Standard errors are clustered on spatial planning regions (96 clusters). $t$-statistics in parentheses; * $p<0.05,{ }^{* *} p<0.01,{ }^{* * *} p<0.001$. 
TABLE 8.

Linear probability model estimates for choosing the closest hospital: Alternative specification

\begin{tabular}{|c|c|c|c|c|}
\hline & \multicolumn{2}{|c|}{ Passed each } & \multicolumn{2}{|c|}{ Passed group } \\
\hline & (1) & $(2)$ & $(3)$ & (4) \\
\hline Distance & $\begin{array}{c}-0.032^{* * *} \\
(-5.72)\end{array}$ & $\begin{array}{c}-0.032^{* * *} \\
(-6.92)\end{array}$ & $\begin{array}{c}-0.032^{* * *} \\
(-5.63)\end{array}$ & $\begin{array}{c}-0.031^{* * *} \\
(-6.53)\end{array}$ \\
\hline Distance $^{2}$ & $\begin{array}{c}0.001^{* *} \\
(2.60)\end{array}$ & $\begin{array}{c}0.001^{* *} \\
(2.94)\end{array}$ & $\begin{array}{c}0.002^{* *} \\
(3.09)\end{array}$ & $\begin{array}{c}0.001^{* *} \\
(2.81)\end{array}$ \\
\hline Distance $^{3}$ & $\begin{array}{l}-0.000 \\
(-1.82)\end{array}$ & $\begin{array}{c}-0.000^{*} \\
(-2.09)\end{array}$ & $\begin{array}{c}-0.000^{*} \\
(-2.43)\end{array}$ & $\begin{array}{c}-0.000^{*} \\
(-2.02)\end{array}$ \\
\hline D-D-I & $\begin{array}{l}0.006 \\
(0.42)\end{array}$ & $\begin{array}{l}0.019 \\
(1.15)\end{array}$ & & \\
\hline Pediatrician & $\begin{array}{c}0.052^{* * *} \\
(4.40)\end{array}$ & $\begin{array}{c}0.063^{* * *} \\
(5.63)\end{array}$ & & \\
\hline Perineal Tear & $\begin{array}{c}0.026 \\
(0.78)\end{array}$ & $\begin{array}{c}0.057^{*} \\
(2.26)\end{array}$ & & \\
\hline M-N Services & $\begin{array}{c}0.029^{* * *} \\
(4.45)\end{array}$ & $\begin{array}{c}0.024^{* * *} \\
(4.04)\end{array}$ & & \\
\hline Care Specialties & $\begin{array}{c}0.013^{*} \\
(2.12)\end{array}$ & $\begin{array}{l}0.001 \\
(0.27)\end{array}$ & & \\
\hline Composite SQ score & $\begin{array}{l}-0.004 \\
(-0.75)\end{array}$ & $\begin{array}{c}0.014^{*} \\
(2.53)\end{array}$ & $\begin{array}{l}-0.002 \\
(-0.40)\end{array}$ & $\begin{array}{c}0.013^{*} \\
(2.42)\end{array}$ \\
\hline Mandatory Quality Assurance & & & $\begin{array}{c}0.036^{* * *} \\
(4.12)\end{array}$ & $\begin{array}{c}0.047^{* * *} \\
(5.04)\end{array}$ \\
\hline Treatment-Related Services & & & $\begin{array}{c}0.021^{* * *} \\
(4.92)\end{array}$ & $\begin{array}{c}0.013^{* * *} \\
(3.71)\end{array}$ \\
\hline Patient characteristics & Yes & Yes & Yes & Yes \\
\hline Hospital characteristics & Yes & Yes & Yes & Yes \\
\hline Hospital fixed effects & No & Yes & No & Yes \\
\hline Observations & & & & \\
\hline
\end{tabular}

Note. - Linear probability model (LPM) estimates for whether a patient chose the closest hospital in her choice set with alternative definition of objective quality indicators. In columns (1)-(2) D-D-I, Pediatrician and Perineal Tear are binary variables indicating whether the hospital passed a required quality threshold according to a specified reference value. In columns (3)-(4), Mandatory Quality Assurance is a summary score of passing the thresholds of D-D-I, Pediatrician and Perineal Tear (out of 3 ) and Treatment-Relevant Services is a combined score of included M-N Services and Care Specialties (out of 11). Patient characteristics include age, \# of Elixhauser conditions, whether a patient was admitted as an emergency case, on a weekend, between 6am-10am on weekdays, and whether the patient was admitted with an secondary ICD-10 code of Z.35 (supervision of high-risk pregnancy). Hospital characteristics include ownership type, \# of beds, if university, if teaching, \# of midwives; Birth-Staff ratio (\# of cases per doctor); share specialized doctors (\# of specialized doctors as a share of all doctors); \# of nurses and an indicator for whether subjective quality was missing. Composite SQ score is based on five satisfaction variables: General, Treatment, Care, Communication, Accommodation. Standard errors are clustered on spatial planning regions (96 clusters). $t$-statistics in parentheses; ${ }^{*} p<0.05$, ${ }^{* *}$ $p<0.01,{ }^{* * *} p<0.001$. 


\section{Appendix A Additional tables and figures}

TABLE A.1.

Classification of Elixhauser Comorbidities

\begin{tabular}{ll}
\hline Variable & Comorbidity \\
\hline el1 & Congestive heart failure \\
el2 & Cardiac arrhythmias \\
el3 & Vascular disease \\
el4 & Pulmonary circulation disorders \\
el5 & Peripheral vascular disorders \\
el6 & Hypertension, uncomplicated \\
el7 & Hypertension, complicated \\
el9 & Paralysis \\
el10 & Other neurological disorders \\
el11 & Chronic pulmonary disease \\
el12 & Diabetes, uncomplicated \\
el13 & Diabetes, complicated \\
el14 & Hypothyroidism \\
el15 & Renal failure \\
el16 & Liver disease \\
el17 & Peptic ulcer disease (excluding bleeding) \\
el18 & AIDS/HIV \\
el19 & Lymphoma \\
el20 & Metastatic cancer \\
el21 & Solid tumor without metastasis \\
el22 & Rheumatoid arthritis/collagen vascular diseases \\
el23 & Coagulopathy \\
el24 & Obesity \\
el26 & Weight loss \\
el27 & Fluid and electrolyte disorders \\
el28 & Blood loss anemia \\
el29 & Deficiency anemia \\
el30 & Alcohol abuse \\
\hline & Drug abuse \\
& Psychoses \\
Depression \\
\hline
\end{tabular}

Note.- Classification of Elixhauser Comorbidities. For detailed construction using ICD-9 and ICD-10 codes, see Quan et al. (2005). 
TABLE A.2.

Linear probability model for choosing the closest hospital: Successive inclusion of satisfaction scores

\begin{tabular}{|c|c|c|c|c|c|c|}
\hline & (1) & (2) & (3) & (4) & (5) & (6) \\
\hline Distance & $\begin{array}{c}-0.032^{* * *} \\
(-6.83)\end{array}$ & $\begin{array}{c}-0.032^{* * *} \\
(-6.87)\end{array}$ & $\begin{array}{c}-0.032^{* * *} \\
(-6.86)\end{array}$ & $\begin{array}{c}-0.032^{* * *} \\
(-6.86)\end{array}$ & $\begin{array}{c}-0.032^{* * *} \\
(-6.83)\end{array}$ & $\begin{array}{c}-0.030^{* * *} \\
(-5.51)\end{array}$ \\
\hline Distance $^{2}$ & $\begin{array}{c}0.001^{* *} \\
(2.87)\end{array}$ & $\begin{array}{c}0.001^{* *} \\
(2.87)\end{array}$ & $\begin{array}{c}0.001^{* *} \\
(2.87)\end{array}$ & $\begin{array}{c}0.001^{* *} \\
(2.87)\end{array}$ & $\begin{array}{c}0.001^{* *} \\
(2.84)\end{array}$ & $\begin{array}{c}0.001^{*} \\
(2.20)\end{array}$ \\
\hline Distance $^{3}$ & $\begin{array}{c}-0.000^{*} \\
(-2.04)\end{array}$ & $\begin{array}{c}-0.000^{*} \\
(-2.02)\end{array}$ & $\begin{array}{c}-0.000^{*} \\
(-2.03)\end{array}$ & $\begin{array}{c}-0.000^{*} \\
(-2.03)\end{array}$ & $\begin{array}{c}-0.000^{*} \\
(-1.98)\end{array}$ & $\begin{array}{l}-0.000 \\
(-1.36)\end{array}$ \\
\hline D-D-I & $\begin{array}{c}0.146^{* *} \\
(3.26)\end{array}$ & $\begin{array}{c}0.151^{* * *} \\
(3.34)\end{array}$ & $\begin{array}{c}0.152^{* * *} \\
(3.38)\end{array}$ & $\begin{array}{c}0.153^{* * *} \\
(3.38)\end{array}$ & $\begin{array}{c}0.149^{* *} \\
(3.25)\end{array}$ & $\begin{array}{l}0.033 \\
(0.65)\end{array}$ \\
\hline Pediatrician & $\begin{array}{c}0.073^{* * *} \\
(5.60)\end{array}$ & $\begin{array}{c}0.070^{* * *} \\
(5.18)\end{array}$ & $\begin{array}{c}0.072^{* * *} \\
(5.38)\end{array}$ & $\begin{array}{c}0.070^{* * *} \\
(5.30)\end{array}$ & $\begin{array}{c}0.072^{* * *} \\
(5.44)\end{array}$ & $\begin{array}{c}0.061^{* * *} \\
(4.10)\end{array}$ \\
\hline Perineal Tear & $\begin{array}{l}0.025 \\
(0.32)\end{array}$ & $\begin{array}{l}0.021 \\
(0.27)\end{array}$ & $\begin{array}{l}0.029 \\
(0.37)\end{array}$ & $\begin{array}{l}0.031 \\
(0.39)\end{array}$ & $\begin{array}{l}0.021 \\
(0.26)\end{array}$ & $\begin{array}{c}0.051 \\
(0.52)\end{array}$ \\
\hline M-N Services & $\begin{array}{c}0.026^{* * *} \\
(4.68)\end{array}$ & $\begin{array}{c}0.026^{* * *} \\
(4.57)\end{array}$ & $\begin{array}{c}0.026^{* * *} \\
(4.59)\end{array}$ & $\begin{array}{c}0.026^{* * *} \\
(4.57)\end{array}$ & $\begin{array}{c}0.026^{* * *} \\
(4.69)\end{array}$ & $\begin{array}{c}0.031^{* * *} \\
(4.98)\end{array}$ \\
\hline Care Specialties & $\begin{array}{l}0.002 \\
(0.42)\end{array}$ & $\begin{array}{l}0.002 \\
(0.32)\end{array}$ & $\begin{array}{c}0.002 \\
(0.46)\end{array}$ & $\begin{array}{l}0.002 \\
(0.42)\end{array}$ & $\begin{array}{l}0.002 \\
(0.34)\end{array}$ & $\begin{array}{l}0.010 \\
(1.78)\end{array}$ \\
\hline General & $\begin{array}{c}0.237^{* * *} \\
(4.07)\end{array}$ & & & & & $\begin{array}{l}-0.021 \\
(-0.14)\end{array}$ \\
\hline Treatment & & $\begin{array}{c}0.144^{*} \\
(2.14)\end{array}$ & & & & $\begin{array}{l}-0.041 \\
(-0.35)\end{array}$ \\
\hline Care & & & $\begin{array}{c}0.137^{*} \\
(2.28)\end{array}$ & & & $\begin{array}{l}-0.226 \\
(-1.19)\end{array}$ \\
\hline Information & & & & $\begin{array}{c}0.134^{*} \\
(2.13)\end{array}$ & & $\begin{array}{c}-0.0957 \\
(-0.53)\end{array}$ \\
\hline Accommodation & & & & & $\begin{array}{c}0.159^{*} \\
(2.14)\end{array}$ & $\begin{array}{c}0.339^{* *} \\
(2.75)\end{array}$ \\
\hline & Yes & Yes & $\mathrm{Ye}$ & $\mathrm{Ye}$ & $\mathrm{Ye}$ & $\mathrm{Ye}$ \\
\hline Hospital characteristics & Yes & Yes & Yes & Yes & Yes & Yes \\
\hline Hospital fixed effects & Yes & Yes & Yes & Yes & Yes & Yes \\
\hline Observations & 225,352 & 225,352 & 225,352 & 225,352 & 225,352 & 225,352 \\
\hline
\end{tabular}

Note. - Linear probability model (LPM) estimates for whether a patient chose the closest hospital in her choice set. Columns (1)-(5) report results where each of the five SQ indicators are included separately. Column (6) reports results from the joint inclusion of all SQ indicators in the model. Patient characteristics include age, \# of Elixhauser conditions, whether a patient was admitted as an emergency case, on a weekend, between 6am-10am on weekdays, and whether the patient was admitted with an secondary ICD-10 code of Z.35 (supervision of high-risk pregnancy). Hospital characteristics include ownership type, \# of beds, if university, if teaching, \# of midwives; Birth-Staff ratio (\# of cases per doctor); share specialized doctors (\# of specialized doctors as a share of all doctors); \# of nurses and an indicator for whether subjective quality was missing. Composite SQ score is based on five satisfaction variables: General, Treatment, Care, Communication, Accommodation. Standard errors are clustered on spatial planning regions (96 clusters). $t$-statistics in parentheses; * $p<0.05,{ }^{* *} p<0.01,{ }^{* * *} p<0.001$. 
TABLE A.3.

Coefficients of variation for quality indicators

\begin{tabular}{lc}
\hline & Coefficient of variation \\
\hline Objective quality indicators $(O Q)$ & 0.118 \\
D-D-I & 0.569 \\
Pediatrician & 0.097 \\
Perineal Tear & 0.428 \\
M-N Services & 0.463 \\
Care Specialties & \\
Subjective quality indicators $(S Q)$ & 0.059 \\
General & 0.038 \\
Treatment & 0.049 \\
Care & 0.045 \\
Information & 0.062 \\
Accommodation & 0.265 \\
Composite SQ Score & \\
\hline
\end{tabular}

NotE.- Estimated coefficients of variation $(\mathrm{CV})$ of the included quality indicators. The CV is defined as the ratio of the standard deviation to the mean of a variable. The Composite SQ score is constructed by application of principal component analysis (PCA) based on 5 satisfaction variables (see section 3.2). 


\section{Appendix B Healthcare provider search}

This appendix provides basic information on the use of the Weisse Liste hospital search portal (https://www.weisse-liste.de). Figure B.1 presents a screenshot of the website's main window in which relevant parts have been marked with letters A-J for reference. The user first types in search criteria in the three white boxes of panel A; the service (Krankheit / Behandlung); the name of a city or postal code (Ort oder Postleitzahl); and the desired maximum distance from the midpoint of the specified area the user is considering (Umkreis). After clicking the yellow search button (Krankenhaussuche), the search engine lists a set of hospitals that meet the specified search criteria together with information about their location and performance indicators.

The website first provides some general information about the selected geographical area, such as the number of hospitals which met the search criteria and a map with their exact locations (B). The hospitals can be ranked (C) in different ways, such as travel distance (Entfernung), general satisfaction (Weiterempfehlung), treatment-related services (Behandlungsrelevante Ausstattung) and quality assurance indicators (Gesetzliche Qualitätssicherung). A separate section for each hospital (D) provides relevant information; name and address together with the distance from the selected postal area (E); average patient satisfaction with the hospital (F); number of treatment-specific annual cases $(\mathrm{G})$; number of treatment-related services provided $(\mathrm{H})$; number of quality assurance indicators passed (I); and number of patient safety and hygiene quality measures passed $(\mathrm{K})$. Detailed quality information can be found by expanding the panel (click Details einblenden). Note that the screenshot shows the information that the search portal currently provides, which is different from the quality information available during the years studied in the article. 
Figure B.1.

Weisse Liste hospital search web portal

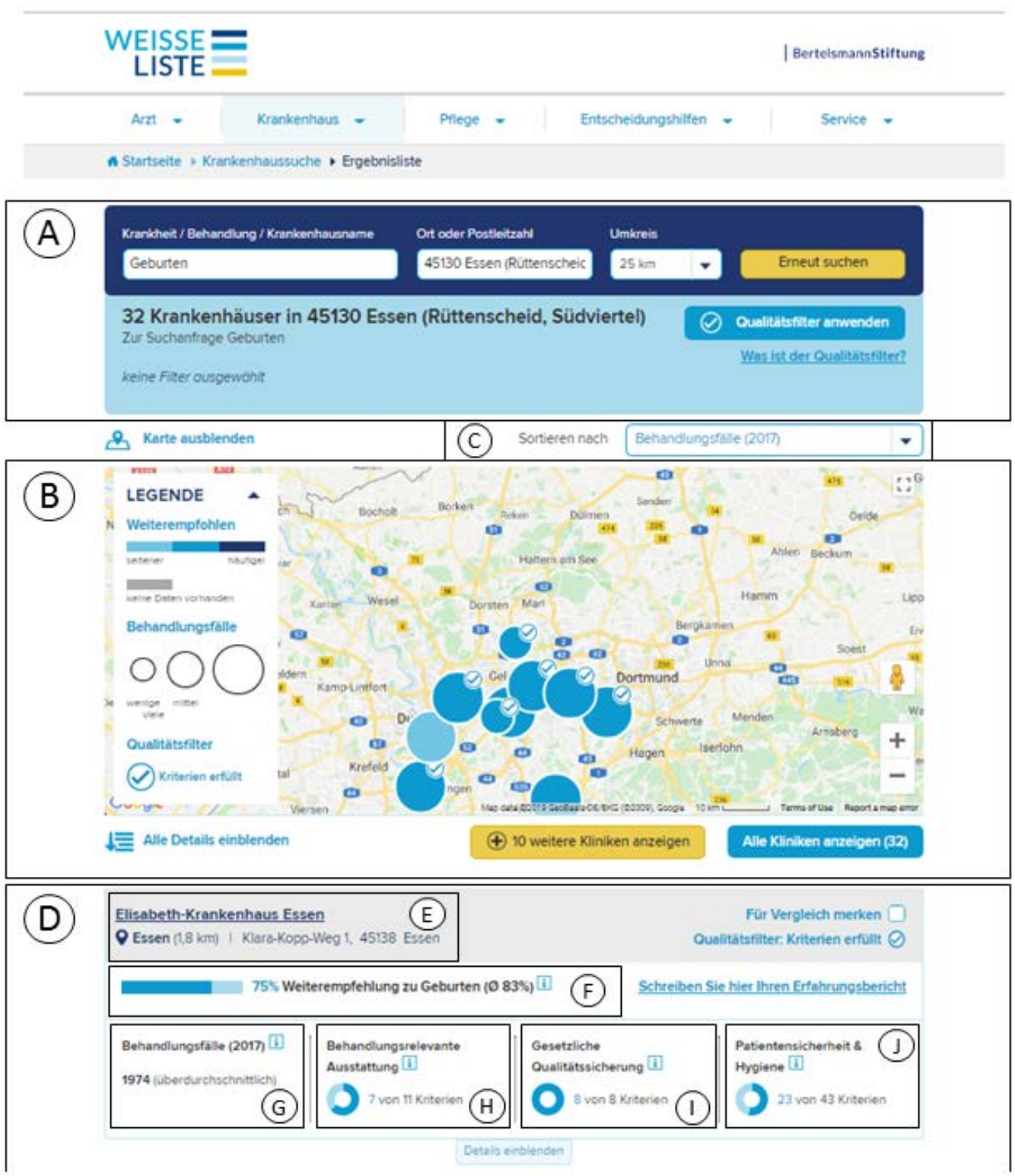

NotE. - Screenshot taken from www.weisse-liste.de. 